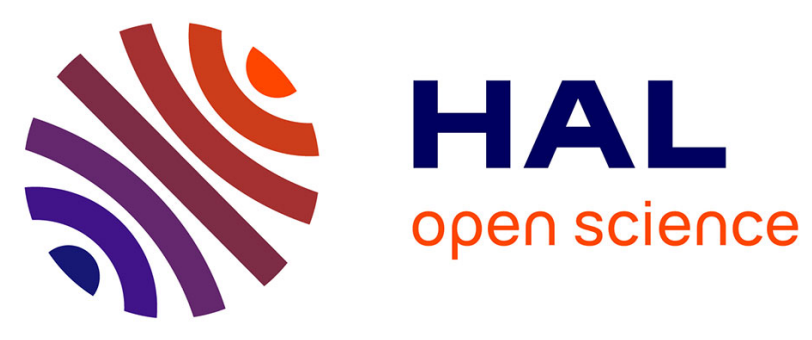

\title{
Aseismic Mining Subsidence in an Abandoned Mine: Influence Factors and Consequences for Post-Mining Risk Management
}

Isabelle Contrucci, Cyrille Balland, Jannes Kinscher, Mustapha Bennani, Pascal Bigarre, Pascal Bernard

\section{To cite this version:}

Isabelle Contrucci, Cyrille Balland, Jannes Kinscher, Mustapha Bennani, Pascal Bigarre, et al.. Aseismic Mining Subsidence in an Abandoned Mine: Influence Factors and Consequences for Post-Mining Risk Management. Pure and Applied Geophysics, 2019, 176 (2), pp.801-825. 10.1007/s00024-0182015-6 . ineris-03319038

\section{HAL Id: ineris-03319038}

https://hal-ineris.archives-ouvertes.fr/ineris-03319038

Submitted on 11 Aug 2021

HAL is a multi-disciplinary open access archive for the deposit and dissemination of scientific research documents, whether they are published or not. The documents may come from teaching and research institutions in France or abroad, or from public or private research centers.
L'archive ouverte pluridisciplinaire HAL, est destinée au dépôt et à la diffusion de documents scientifiques de niveau recherche, publiés ou non, émanant des établissements d'enseignement et de recherche français ou étrangers, des laboratoires publics ou privés. 


\section{Aseismic mining subsidence in an abandoned mine: influence}

\section{factors and consequences for post-mining risk management}

Isabelle Contrucci (1), Cyrille Balland (1), Jannes Kinscher (1), Mustapha Bennani (1*), Pascal Bigarré (1) and Pascal Bernard (2)

(1) Institut National de l'Environnement Industriel et des Risques (Ineris), Ecole des Mines de Nancy, Campus ARTEM CS14234, 54042 Nancy Cedex, France. E-mail: Isabelle.Contrucci@ineris.fr

(2) Equipe de Sismologie, Institut de Physique du Globe de Paris, 1, rue Jussieu - 75238 Paris cedex 05, France. E-mail: bernard@ipgp.fr

$\left({ }^{*}\right)$ Now at GEODERIS, 1 Rue Claude Chappe, 57075 Metz, France. E-mail: Mustapha.Bennani@geoderis.fr

Corresponding author : Isabelle.Contrucci@ineris.fr Isabelle Contrucci

Accepted xxx. Received zzz; in original form yyy

Abstract:

In the Lorraine area of eastern France, decades of iron-ore mining from 1850 to 1997 have left vast underground cavities beneath or in the vicinity of urban areas. Several major collapses occurred in the southern part of this iron-ore basin in the 1990s, after the mine closure and the flooding of underground mine workings. Following these large-scale collapses, the French government initiated a strategy of post-mining risk management to prevent and control risks associated with these ground failures. The high-risk zones are secured either by reducing the vulnerability while the moderate risk zones are monitored for public safety purposes by using in situ monitoring. This monitoring relies mainly on real-time microseismic systems, to detect precursors to a rapid large-scale collapse. After the progressive closing and then flooding of the northern iron basin ending in 2008, subsidence was observed in a town of the Lorrain basin in 
autumn of 2009. However, this local subsidence, with a low velocity of few centimeters per month, was not clearly detected by the borehole microseismic monitoring station located nearby. Only some microseismic events were recorded, which could not be unambiguously related to the beginning of the subsidence event. To better understand this lack of microseismic precursor a geophysical investigation was launched. A calibration blast experiment was carried out from a remaining old underground access in order to answer to the following questions: (1) what is the seismic wave attenuation field?; (2) what is the minimum source power that can be detected by the sensors?; (3) what is the impact of the geology, the faults corridor and the integral pillar extraction zone on the wave propagation field? The results of this study show strong anelastic attenuation of the seismic waves though the monitored overburden most likely related to the extensive fault system intersecting the study site. Strong attenuation might explain the lack of detected microseismicity during the subsidence event. In addition, low frequency microseismic events associated with the very slow subsiding movements might have not been detected by the used high frequency recording instruments. In order to clarify this issue, a mobile GPS monitoring system was designed and tested to address this type of situation in future.

Key words: microseismic; monitoring; post-mining risk; subsidence; anelastic attenuation; mine closure. 


\section{INTRODUCTION}

In the Lorraine area in eastern France, decades of iron-ore mining from 1850 to 1997 have left vast underground chambers and pillars beneath urban areas. These residual voids are estimated to be 500 million $\mathrm{m}^{3}$ in total size. Several major collapses occurred in the southern part of this ironore basin in the 1990s after the mine closure (Didier, 2007). These events happened a few months after the progressive rise of the water level in the underground workings, which was caused by the pumping stoppage of the mine water. Major and brutal collapses were provoked by the failure of residual abandoned underground pillars. Surface subsidence could reach two meters like in the Auboué area (Deck, 2002). More than five hundred buildings have been damaged due to these disorders and many had to be destroyed.

Following these large-scale collapses, the French government and the local authorities initiated a strategy of post-mining risk management to prevent and control the risks associated with these ground failures. By this strategy, first hazardous zones are identified, which is assessed by defining ranks according to their vulnerability and exposure of human infrastructure and activity. Then, the high risk zones are secured either by reducing the hazard or by surveying the hazard by means of microseismic monitoring (Bennani et al., 2003). Microseismic monitoring in real time has been found to be an efficient tool to assess stability of many underground mining operations (Mendecki, 1996; Urbancic and Trifu, 2000; Orlecka-Sikora et al., 2012; Li et al., 2016), to detect microseismic activity related to precursor phenomena of large-scale underground and surface collapses (Malovichko et al., 2009; Malovichko et al., 2010; Contrucci et al., 2011), as well as to anticipate smaller scaled hazardous processes as roof fracturing, block falls, and dissolution processes in karst and evaporite environments (Dahm et al., 1998; D. A. Malovichko et al., 2009; D. A. Malovichko et al., 2010; Trifu and Shumila, 2010; Kinscher et al., 2015; Kinscher et al., 2016). The potential of the microseismic monitoring was furthermore assessed and validated in the geological context of the Lorrain basin by means of locally provoked small scaled mining collapses during the "Terres Rouges" experiment in 1997 (Senfaute et al., 2000; Couffin et al., 
2003). Calibration blast were performed in the iron ore Lorrain basin to calibrate microseismic monitoring system (Contrucci et al., 2010) to adjust, among other geophysical parameters, velocity models as it is perform classically to optimize monitoring (Bardainne and Gaucher, 2010).

The used monitoring systems were designed to monitor relatively rapid collapse, with a subsidence velocity of about 1 to $10 \mathrm{~cm}$ per hour. Since 1998, Ineris (National Institute for the Industrial Environment and Risks) deployed over 30 microseismic real time monitoring networks in the Lorrain iron-ore basin, with focus on a northern high risk area. These deployments were installed to anticipate potential collapsing events related to gradual flooding of the northern basin, starting in December 2005 and ending in March 2008. A calibration blast experiment was performed on a part of these monitoring systems, in 2010 after the stabilisation of the flooding of the mine. The objective was to ensure the sensitivity of monitoring devices and to calibrate the data processing like localization and source energy from artificial blast signals (Contrucci et al., 2010; Bigarré et al., 2011).

So far no significant microseismic activity was recorded in the monitored areas that could be associated with the origin of a mining collapse. Nevertheless, a significant subsidence event was observed in a monitored town in the fall of 2009 , located in the south-western edge of a flooded, abandoned chamber and pillar mining sector. For confidentiality reasons, the name of the site will remain anonymous. Local subsidence was characterized by slow velocity of some few centimeters per month. This subsidence was evidenced by the local levelling network that is surveyed every two years, and by the claim of inhabitant who observed fractures in their habitations. Despite to this significant surface deformation only few microseismic events have been detected by the local microseismic monitoring station.

During a first investigations about the cause of the absence of significant microseismicity, a technical origin (e.g. power problem of the acquisition system or sensors) could be widely excluded. Consequently, further geophyiscal investigations have been demanded by the Regional 
Organisation of Environment, Land Settlement and Housing (DREAL) under the recommendation of the Public Interest Group for support and expert studies (GEODERIS) and under the supervision of the French Geological Survey (BRGM). One major objective of this program was to re-evaluate the potential of microseismic monitoring in this particular case. Specifically, it needs to be clarified if the absence of microseismicty is related to aseismic deformation/subsiding processes (e.g. possibly related to a strongly fractured overburden) or/and whether the detection capacity of seismic sensors is affected by stronger attenuation effects resulting from the partially water-filled underground openings.

In order to address this discussion, Ineris carried out calibration blasts campaign to respond to the following problem specific questions: (1) what is the quality of coupling of the probe located in the borehole with the ground? (2) What is the velocity and wave attenuation field? (3) What is the minimum source power that can be detected by the sensors? (4) What is the impact of the geology, the faults corridor and the fully-caving zone on the wave propagation field?

\section{RELATION OF MINING FLOODING AND MICROSEISMICTY : STATE OF}

\section{THE ART}

In abandoned mines, exploited by chamber and pillar method, it is suggested that stress redistributions are mainly due to the rise and flooding of groundwaters which can lead to reactivations of natural faults or faults created by the past mining activity, as well as to the failures of old mine pillars. Flooding usually results from the shutdown of mining ground water pumping operations after the mine closure. After reaching an equilibrium level, the water level can vary in the mine depending on the seasonal precipitation distribution.

Unfortunately, few examples can be found in literature documenting long term instabilities of flooded abandoned mines and related induced microseismic activity allowing for a better understanding of this relation and more accurate hazard assessment (Miller et al., 1989; Ogasawara et al., 2002; Bennani et al., 2003; Couffin et al., 2003; Contrucci et al., 2010; Goldbach, 2010; Srinivasan et al., 2009). Goldbach (2010) described the effects of flooding in 
deep gold mines in South Africa over a period of five years. In their study, the authors found that seismicity intensified abruptly 14 months after the start of flooding. In the following, seismic activity increased for a period of six months until the focal microseismic depths joined the water level. The observed maximum magnitude was 3.3. The authors finally suggested that seismic activity was related to the reactivation of faults by creating an excess of water pressure along the fault planes. Ogasarawa (2002) describes the long-term seismicity of a mine in Japan after a flooding period of five years. During this period, only 60 events were detected with magnitudes below zero. The authors found a clear correlation between seismicity and strong rainfalls.

Another example of flooding induced microseismicity was observed in the abandoned mine of Salsigne (France) in November 15th, 2011, where a seismic event of magnitude 2.5 was recorded (Dominique et al., 2012). In this study, it was furthermore suggested that the weakness of the mine working also played a role in triggering seismicity during the flooding (Alheib, 2012). The origin of the event was attributed to the rupture of several underground pillars, as a consequence of fault reactivations located at the mining site. In the abandoned coal basin of Gardanne (France), microseismicity has been recorded from 2008 until now. The recorded events are mainly located at the limit of a flooded area, and seemed to be induced by water level variations. In November 2012, Decembre 2014 and at the end of 2016, events reached local magnitudes of up to 2.2 (Contrucci et al., 2013). Nonetheless, the physical and mechanical origin of seismicity is still under study. We can as well cited the case the surface deformation induced by water infill in the abandoned coal mines in Limburg (The Netherlands) observed by satellite radar interferometry (Caro Cuenca et al., 2013). This region undergone a significant subsidence that occurred since the beginning of 1900s and is estimated to be in order of several meters. Another example is the eastern part of the abandoned Teutschenthal potash mine (near Halle, SachsenAnhalt, Germany) where a strong seismic event, $M_{1}$ 4.8, were recorded on September 11, 1996 (Cesca et al., 2013). The mine was stopped sine 2 years before the collapse. A maximal vertical coseismic subsidence of about $45 \mathrm{~cm}$ was observed at the surface. 
Note that there are also a few case studies of large instrumented mine collapses or subsidence in the literature, especially with microseismic monitoring. Usually these case studies are related to mining operation accidents (Malovichko et al., 2001) or how to stabilize a site (Zamfirescu et al., 2007a; Zamfirescu et al., 2007b; Trifu and Shumila, 2010) or to triggered collapse of underground salt solution mining cavities as a part of the mining scheme (Contrucci et al., 2011). Nevertheless, the last paper shows that microseismic tools are relevant to monitoring rapid collapse with a subsidence of several centimetres per hour.

\section{GEOLOGICAL AND MINING CONTEXT OF THE LORRAINE IRON-ORE}

\section{$\underline{\text { BASSIN }}$}

The Lorraine iron-ore basin, located on the eastern boundary of the Paris basin, extends on approximately one hundred kilometres from North to South and twenty to thirty kilometres from East to West. The Lorraine iron-ore basin formations have a marine origin. The basin is cut by major faults of several kilometres long oriented NE-SW. The iron-ore series and its cover show a dip of few degrees towards the South-West, except near the major fractures where the local dip can reach $10^{\circ}$.

The iron-ore series belongs to the Aalenian stage. The marly-carbonated cover belongs to the lower and middle Bajocian. Overall, the various geological formations found in the basin are as follows (Bennani and Homand, 2004): (1) the Doncourt oolitic Limestones; (2) the Jaumont oolitic Limestones; (3) the upper and lower Polypiers Limestones; (4) the Haut-Pont Limestones; (5) the Ottange Limestones; (6) the Charennes Marls; (7) the iron-ore formation. The geometry, thickness and extent of these series can vary laterally rapidly. Not all these formations are found in the entire basin. The iron-ore formation with a thickness between 1 and $65 \mathrm{~m}, 40 \mathrm{~m}$ on average (Montagne et al., 1992), can be considered as alternating between marls and ores. Nine ore layers have been counted in the entire basin (Maubeuge, 1955), named using colours. Usually two to three layers were exploited with the chambers and pillars operating method below urban areas, with pillar extraction or robbed pillar method outside urban areas. A total of 3.1 billion 
tonnes of iron ore were extracted, i.e. about 1.2 billion $\mathrm{m}^{3}$ over a surface area of $1700 \mathrm{~km}^{2}$.

\section{SITE CHARACTERISTICS}

\subsection{LOCAL MINING CONTEXT}

The overburden of the site is $\sim 160$ meters thick and is formed by alternation of marls and limestones (Figure 2). Mechanical properties of the formations are resumed in Table 1 (GISOS, 2007). The mine was exploited by the chambers and pillars method, beneath inhabited areas. Three ore layers exploited were: yellow, grey and black. A set of normal faults cut the studied site and forms a corridor with an average orientation of $\mathrm{N}^{\circ} 5^{\circ}$ (Figure 1). The main structure of this fault system is located at the northwestern edge of the mine (Figure 1). The vertical displacement of this fault was estimated with $40 \mathrm{~m}$ towards the SE. This fault system cuts the Bajocien sedimentary formations located above the iron formation (Figure 2). Downstream from the main fault (southwest, south and east edges) the mining works were carried out by integral removal of mine pillars (robbed pillar method) within the gray layer, leading to the collapse of the entire overburden.

\begin{tabular}{|c|c|c|c|}
\hline & $\begin{array}{c}\text { Young's } \\
\text { modulus: } \mathrm{E} \\
(\mathrm{MPa})\end{array}$ & $\begin{array}{c}\text { Poisson's ratio } \\
\nu\end{array}$ & $\begin{array}{c}\text { Density }: \varrho \\
(\mathrm{kg} / \mathrm{m} 3)\end{array}$ \\
\hline Limestones & 21125 & 0,3 & 2460 \\
\hline $\begin{array}{c}\text { Marly } \\
\text { Limestones }\end{array}$ & 14840 & 0,3 & 2460 \\
\hline Marl & 13863 & 0,3 & 2560 \\
\hline Socle & 19025 & 0,3 & 2665 \\
\hline
\end{tabular}

Table 1 : Mechanical characteristics of the overburden

Two major risks zones have been identified at the studied site, named the zone R136C1 and the zone R136A1 (Figure 1and Figure 5), which are suspicious to produce progressive subsidence, as qualified by GEODERIS. To monitor these zones three permanent microseismic station unit, named Lilas, Puits-Armand and Groseilliers were installed. Each station unit consists of three 40 $\mathrm{Hz}$ geophones, cemented into boreholes including: one 1D probe at the surface, one 1D probe about $25 \mathrm{~m}$ below the surface and one 3D probe about $50 \mathrm{~m}$ below the surface. Note that one 
4.5 $\mathrm{Hz}$ 3D probe is additionally installed at the Lilas station unit at $\sim 45 \mathrm{~m}$ depth. The orientation of the $3 \mathrm{D}$ probe was measured during borehole installation by using a compass. The stations are connected to an acquisition unit, which automatically detects, records and transfers data to the monitoring central site of Ineris.

In the monitored subsidence affected zone (Zone R136C1, Figure 1), only the gray ore layer was exploited. The depth of this layer below the surface is about 160 meters. The ratio of extraction was approximately $47 \%$. The mining works, exploited by chambers and pillars, are today flooded at $\sim 208 \mathrm{~m} \mathrm{NGF}$ level, and dips at $2.5^{\circ}$ approximately (NO). This configuration prevents the underground access at the zone located directly below the subsided area (Figure 1).

\subsection{SUBSIDENCE DESCRIPTION}

The area has a levelling network that is surveyed every two years (Figure 3). The regular survey of February 2009 showed, in comparison to the previous survey in August 2007, a surface subsidence of about 1 to $3 \mathrm{~cm}$ on the points R106 and R107 to R120 (Figure 3 and Figure 4). These variations occurred over a period of 18 months and were considered to be insignificant at that time. As suggested from observations made in December 2009, these variations were probably related to the beginning of the subsidence (GEODERIS, 2010). Indeed, after the disorders observed in October 2009 in private individuals houses, topographic leveling sampling has been intensified with monthly measurements since December 2009, and the installation of additional leveling points (Figure 4).

The subsidence basin is located in the south of the risk zone. Until July 2011, no lateral extension of subsidence had been observed. Contrastingly, in August 2011 measurements showed an extension of the depression towards the east (points R108, R109b and R124) with a variation of $30 \mathrm{~mm}$ compared to the last measurements (Figure 3). This extension was confirmed by the surface levelling carried out in April 2012.

Altimetric measurements of August and September 2011 showed, as well, an increased subsiding velocity at several leveling points (Figure 3 and Figure 4). The subsidence velocity varied from 1 
to $2 \mathrm{~cm} /$ month, between December 2009 and July 2011, to a peak of more than $10 \mathrm{~cm} / \mathrm{month}$ in September 2011. Then the subsidence velocity decreased reaching today's velocities below 2 $\mathrm{cm} /$ month. In total, the R121d leveling point detected significant vertical displacements as part of a subsiding basin formation with an amplitude of $\sim 70 \mathrm{~cm}$ measured in April 2012 (Figure 3 and Figure 4).

\section{MICROSEISMIC ACTIVITY : APPLIED METHODS AND RESULTS}

The seismic activity was very weak over the entire period from November 2009 until May 2012, it (Figure 4 and Figure 5). Over this period, 38 events were recorded in total, including 2 in 2009, 10 in 2010 and 21 in 2011 and 5 in 2012. The 2010 microseismic activity was diffused in time, with less than one event per month on average over the entire year (Figure 4). Between the $1^{\text {st }}$ January 2011 and the $31^{\text {st }}$ December 2011, the microseismic activity increased in July and August with 10 events (Figure 4 and Figure 5).

\subsection{MICROSEISMIC EVENT DETECTION}

The detection and acquisition of the microseismic events is a triggering system. In this approach, the first parameters considered is the number of triggering channels exceeding an amplitude threshold on at least 2 any channels on the 3D sensors of the network. The second parameter are the amplitude thresholds, that are adjusted to the recording conditions at each station of the network. These amplitude thresholds are set according to the level of seismic background noise that can vary according to the urban environment and the level of recurrence of artifacts.

When an event is detected, all the channels of the microseismic network are recorded for a configurable period, set at $0.5 \mathrm{~s}$ in our case. The trigger parameters are only modified in the case of changes in the level of background seismic noise, recurring surface noise, in case of control and maintenance operation, etc.

From the end of 2007 to November 2009 the following trigger parameters were chosen, according to the seismic noise: $\pm 1 \cdot 3 \cdot 10^{-6} \mathrm{~m} \cdot \mathrm{s}^{-1}$ at the Puits-Armand station; $\pm 3 \cdot 3 \cdot 10^{-6} \mathrm{~m} \cdot \mathrm{s}^{-1}$ at the Lilas station; $\pm 6.5 .10^{-6} \mathrm{~m} \cdot \mathrm{s}^{-1}$ at the Groseilliers station. In November 2009 (following the 
observation of the subsidence), the thresholds of the Lilas and Groseilliers stations were lowered respectively to $\pm 1 \cdot 6 \cdot 10^{-6} \mathrm{~m} \cdot \mathrm{s}^{-1}$ and $\pm 6 \cdot 5 \cdot 10^{-7} \mathrm{~m} \cdot \mathrm{s}^{-1}$.

\subsection{MICROSEISMIC EVENT LOCATION}

The location was performed using the SYTMISauto software developed by Ineris. This location is based on the combination of the microseismic wave arrival times as well as the polarisation angles, in order to determine the hypocenter. Indeed, the integration of polarisation angles enables to locate an event with few probes, i.e. one 3D probe and one 1D probe if only $\mathrm{P}$ waves are detected or a single 3D probe if $\mathrm{P}$ and $\mathrm{S}$ waves are recorded (Abdul-Wahed et al., 2001). The implemented localisation algorithm is based on a probabilistic approach to solve the inverse problem (Tarantola and Valette, 1982). It consists in maximising a probability density function $(p d f)$ of the hypocenter at a given point using L2 norm. This is done by minimizing the misfit between measured and calculated arrival times and polarisation angles. The hypocenter with the maximum likelihood is determined by using the Oct-Tree non-linear method (Lomax and Curtis, 2001), based on a successive division of space into cells depending on the value of the probability calculated for each cell. This approach is used to completely solve the inverse problem and thus provides a representation of the overall $p d f$ of the localisation. The most probable hypocentre corresponds to the $p d f$ maximum.

Velocity model used to perform the location was define according to the analysis made in this study (Table 2 and $\int$ 7.2). To take into account uncertainties related to the velocity model, an error with value of $\pm 0.002 \mathrm{~s}$ is introduced on all travel times, which corresponds to an error of $\pm^{\circ} 70 \mathrm{~m} / \mathrm{s}$ for a wave travelling at $3500 \mathrm{~m} / \mathrm{s}$ over a distance of $350 \mathrm{~m}$. Errors on the incidence angles are assessed at \pm 10 based on previous work (Contrucci et al., 2010); manual picking error is set at $\pm^{\circ} 0.005 \mathrm{~s}$.

\subsection{SOURCE PARAMETERS ESTIMATION}

Source parameters, such as moment magnitude $\left(\mathrm{M}_{\mathrm{w}}\right)$ and corner frequency $\left(\mathrm{f}_{\mathrm{c}}\right)$, have been 
calculated using a frequency-domain approach, following the methodology proposed by Kinscher (2015) and considering the P-wave spectra which are available for all the events detected. Parameters determination consists in minimizing the misfit between observed spectra and Brune's model theoretic spectra (Brune, 1970):

$$
u(f)=M_{0} \frac{R}{4 \pi \rho V_{P}{ }^{3}} \frac{1}{1+\left(f / f_{c}\right)^{2}}\left[\exp \left(\frac{-\pi D f}{Q V_{P}}\right) \frac{1}{D}\right]
$$

where $u(f)$ is the displacement spectra, $M o$ is the seismic moment, $\rho=2500 \mathrm{~kg} / \mathrm{m}^{3}$ the rock mass density, $V_{P}$ the $\mathrm{P}$-wave velocity, $f_{c}$ the corner frequency, $\mathrm{D}$ the source-receiver distance; $\mathrm{R}=0.4$ for the P-wave radiation pattern respectively and Q the quality factor.

To improve the fitting, displacement spectra are converted to moment magnitude spectra (Kinscher, 2015). Misfit between observed and theoretic spectra is minimized using a grid search technique varying $\mathrm{M}_{\mathrm{w}}, \mathrm{f}_{\mathrm{c}}$ and the quality factor $\mathrm{Q}$ in a range of predefined values. In order to be consistent with estimation obtained in this study ( $\mathbb{( 1 0 . 2 )}$ the Q-factor was allowed to vary between 1 and 100. The computation is performed by optimization, taking into account only 3D $40 \mathrm{~Hz}$ probes. Variation ranges for $\mathrm{M}_{\mathrm{w}}$ and $\mathrm{f}_{\mathrm{c}}$ have been determined from available recordings, choosing a moment magnitude range between -3 and 3 , while the corner frequency range has been set between 1 and $100 \mathrm{~Hz}$.

Source radius $\mathrm{r}_{0}$ was estimated according to Brune's model for $\mathrm{P}$ waves using this formula :

$$
r_{0}=\frac{k_{p} V_{p}}{2 \pi f_{c}}
$$

Where $\mathrm{k}_{\mathrm{p}}=1.88$ is the model constant, $\mathrm{V}_{\mathrm{p}}=3000 \mathrm{~m} / \mathrm{s}$ the $\mathrm{P}$ wave velocity and $f_{c}$ the corner frequency.

\subsection{RESULTS}

Most of the microseismic events are located to the south-east, close to the Groseilliers station (Figure 5). In August 2011, the transient acceleration of the subsidence from 2 to $10 \mathrm{~cm} /$ month was accompanied by the detection of about fifteen microseismic events. These events were 
detected with detection thresholds at extremely low values $\left(6.5 .10^{-7} \mathrm{~m} \cdot \mathrm{s}^{-1}\right.$ for Groseilliers station) set for the subsidence monitoring. These events show low magnitudes, between $-0,45$ and -1 (Figure 4) and did not cause any concern. At this period, the value of the strongest magnitude observed was $\mathrm{Mw}=-0,45$. This event was located close to Groseilliers station at $\sim 150 \mathrm{~m}$ of epicentral distance and $\sim 320 \mathrm{~m}$ from Lilas station. The signal on the Lilas station is just above the detection thresold $\left(1.6 .10^{-6} \mathrm{~m} \cdot \mathrm{s}^{-1}\right)$, and the signal to noise ratio is very low.

Thus, during this main acceleration phase of the subsidence, the microseismic activity remained extremely weak and would not have been detected if the previous detection thresholds $\left(6.5 .10^{-6}\right.$ $\mathrm{m} . \mathrm{s}^{-1}$ ) had been maintained. It means that this subsidence phenomena did not generate strong events. Indeed, on the all period, detected moment magnitude varying between $-1,7$ and $-0,45$ and the source radius vary between 10 and 70 meters, with a mean of 20 meters.

\section{INSTRUMENTATION AND CALIBRATION BLAST EXPERIMENT}

As mentioned before a calibration blast experiment was carried out to investigate the reason of this weak seismic activity, to better understand the subsidence mechanism, as the hypothesis of a failure of the equipment was rejected. Calibration blasts were carried out on the 21th and 22th September 2010. The blast charges were selected between $100 \mathrm{~g}$ and 10,000 g. In addition to the blasts experiment, a (500 kg) weight drop campaign was performed in the accessible Louise Gallery (Figure 6).

To better characterize the wave propagation across the overburden, additional acquisition systems were installed at the surface and in the mining workings, to complement the permanent monitoring network (stations Lilas, Groseilliers and Puits-Armand). Two temporary seismic streamers with 84 and $24,50 \mathrm{~Hz}$ geophones, respectively, were installed at the surface. The digitizer consisted of four devices: one StrataVisor ${ }^{\circledR}$ seismograph and three stand-alone geode recorders. The objective of the first seismic streamer of 84 geophones was to record a large number of ray paths to characterize the seismic velocity field of the overburden (Figure 6). The 
second streamer (24 geophones) was installed at the top of the collapsed area (Figure 6).

In addition, a temporary monitoring network was installed in the accessible mine workings. It consisted of two stations, each equipped with a geophone, a microphone and a hydrophone, three components broadband station and a piezometer. The location of these instruments is shown on Figure 6.

The blasts were carried out in drillings into the mine workings, at $\sim 160$ meters depth, using explosive dynamite sticks of EURODYN 2000. The blasts were mainly performed east of Lilas and Groseilliers stations and to the west of the subsidence area. Blasting below the subsiding zone was impeded by the fact that the mine workings were flooded. Moreover, the non-flooded closest areas showed an air saturated in $\mathrm{CO}_{2}$, which prevented the carrying out any blast closed to the subsidence area.

The hypocentral distances between the blasts and the stations (of the operational monitoring system) varied between $100 \mathrm{~m}$ and $690 \mathrm{~m}$.

The first objective was to test the minimal charge which could be detected by any microseismic station. For that purpose, several blasts were carried out in the same place with charges ranging from $100 \mathrm{~g}$ to $500 \mathrm{~g}$. Some of the blasts were equidistant from Lilas and Groseilliers stations (blasts number $5 \mathrm{a}$ and $5 \mathrm{~b}$, Figure 6). These equidistant blasts allowed to compare the seismic response of each station without any correction of the geometrical attenuation, assuming that attenuation attributes are similar along the different source-receiver paths.

Blasts with high charges (10 kg of dynamite) were conducted for tomography purposes. These blasts were located underground, in the mine workings, following an "L" geometry, symmetric to the "L" geometry of the seismic streamer installed at the surface (Figure 6).

\section{VELOCITY ANALYSIS: APPLIED METHOD AND RESULTS}

Here we present the methods used for velocity calculations, to estimate 1D layered models. Estimations of velocities of the overburden will help to characterise the wave propagation conditions, especially the wave transmission of the wave from the mine working to the 
monitoring station.

\subsection{D SEISMIC VELOCITY MODEL: DATA AND METHODS}

Data used was the P-wave and the incident angles of shots recorded at the permanent monitoring stations. Only incident angles measured at 3D Lilas station were used, because of a tilt existing on the incident angles measured at the Groseillers 3D station. Indeed, incident angles measured at this station show the same value $\left(\sim 55^{\circ}\right)$ independent of the position of the blast, attesting the presence of a local velocity anomaly.

Errors considered for inversions are of $0.005 \mathrm{~s}$ on P-wave arrival times, and $10^{\circ}$ on the incident angles. For the computation of the velocity models, shots showing the most significant residues, $(>0.01 \mathrm{~s})$ which are at least two times greater than the error, were removed from the inversion. Thus, on the 26 shots made, 15 were selected for the 3-layer velocity model and 17 for the model with a 4-layers velocity model.

The model inversion was performed by means of SYTMISvel software. Inversion was constrained by a priori information on geological layering and thickness provided (Contrucci et al., 2010). During inversion numerous velocity models were explored, which were generated randomly using a Monte-Carlo approach (Lomax and Snieder, 1995). The accuracy of these models was estimated by using a least-square misfit function (L2-norm) between calculated and observed data. For minimization a global approach was used, since travel times are non-linearly related to the velocities of the individual layers.

\subsection{TIME-DISTANCE GRAPH AND 1D VELOCITY MODEL}

Before running the SYTMISvel software, we check the consistency of the P-wave arrival times by plotting the time-distance graph (hodochrone). The slope of these curves corresponds to the slowness, which is the inverse of the velocity. These curves show a good consistency measured on all devices located in the mine workings (Figure 7-a), on permanent network stations (Figure 7-b) and on temporary geophone antennae deployed at the surface (Figure 7-c). The average velocity determined from arrival times, recorded by the devices located in the mining works, is in 
the order of $3350 \pm 70 \mathrm{~m} / \mathrm{s}$. The average velocity determined from arrival time of the permanent network is $3500 \pm 40 \mathrm{~m} / \mathrm{s}$. The average velocity is about $3300 \pm 40 \mathrm{~m} / \mathrm{s}$ from the arrival times, measured on the temporary surface geophone.

The velocity field was modelled by three and four layers corresponding to the main geological formations $(\mathbb{S} 5.1)$ using SYMISvel software. The three layers model considers iron formations and marls of Charennes as a single layer. The four layers model distinguishes iron formation and marls of Charennes. Best velocity models, based on time residues, are summarized in Table 2. Figure 8-a-b shows the statistical distribution of velocity models and the time residues associated. In both models, the sub-surface velocity is in the order of $1900 \mathrm{~m} / \mathrm{s}$. For limestones, velocities range from 2900 to $3100 \mathrm{~m} / \mathrm{s}$. The marls of Charennes layer shows a velocity of $3700 \mathrm{~m} / \mathrm{s}$ in the 4-layer model. The velocity of the last layer of the two models was fixed between 3200 and 3300 $\mathrm{m} / \mathrm{s}$ to ensure compatibility with measurements recorded by the sensors located underground.

Without including the sub-surface, the 4-layered model shows an average velocity $(3410 \mathrm{~m} / \mathrm{s})$ which is higher than the average velocity of the 3-layers model $(3137 \mathrm{~m} / \mathrm{s})$. The 4-layers model is more compatible with the velocity determined from time-distance graphs deduced from the three different networks.

Note that the velocity obtained on this site are quite similar to those measured on the neighbouring site whith a similar geology (Contrucci et al., 2010). On the other hand, velocity measurements made on rock samples in laboratory show lower velocities of 1965 to $2680 \mathrm{~m} / \mathrm{s}$ for the Charennes marl formation (Homand and Dagallier, 2004), as compared to our study. These values should nevertheless be considered with caution because they were estimated from rock samples. Moreover, Charennes marls and all other geological formations have a high variability in their mechanical properties across the iron basin (Bennani and Homand, 2004), and therefore have high variability in their seismic velocities. 


\begin{tabular}{|l|l|c|c|c|c|}
\hline \multicolumn{2}{|c|}{ Site } & Surface & $\begin{array}{c}\text { Bajocien } \\
\text { limestones }\end{array}$ & $\begin{array}{c}\text { Charennes } \\
\text { Marls }\end{array}$ & $\begin{array}{c}\text { Iron ore } \\
\text { formation }\end{array}$ \\
\hline 3-layers velocity model & Thickness (m) & 27 & 89 & \multicolumn{2}{|c|}{42} \\
& Velocity (m/s) & 1907 & 2975 & \multicolumn{2}{c|}{3298} \\
& Error (m/s) & 385 & 188 & \multicolumn{2}{c|}{28} \\
\hline 4-layers velocity model & Thickness (m) & 27 & 89 & 33 & 40 \\
& Velocity (m/s) & 1867 & 3137 & 3695 & 3398 \\
& Error (m/s) & 373 & 198 & 208 & 56 \\
\hline
\end{tabular}

Table 2 : summary of the velocity model characteristics with three and four layers.

\section{TOMOGRAPHY ANALYSIS: APPLIED METHOD AND RESULTS}

\subsection{D VELOCITY TOMOGRAPHY CALCULATION}

The principle of $2 \mathrm{D}$ seismic tomography is to reconstruct the velocity field along a plane crossed by many seismic rays. The plane is then cut into cells and associated with a value of the velocity best fitting the ray travel times. For this purpose the TOMSIS $^{\circledR}$ software $(2 \mathrm{D}$ seismic tomography software, (Balland et al., 2009) was used. Ray path rebuilding is based on the algorithm from (Um and Thurber, 1987). For tomographic inversion, the global matrix method and an initial velocity field were used. Another optimization factor, related to the matrix inversion, helps to improve the convergence quality. In the iterative inversion procedure, at each step, a new initial velocity field is generated and as well as ray paths coming from the previous iteration. Iterative inversions are performed until the differences between the initial and resulting velocity field become insignificant. A disadvantage of this iterative processing is the artificial increase of the velocity extremum caused by the arrival time disturbance. So, the best action is to stop the iterative processing as soon as possible. A least, the tomographic picture is corrected with the global anisotropy observed on all rays with a method that had estimated the weak velocity anisotropy (Thomsen, 1986).

The estimation of the velocity field by seismic tomography method, requires a larger number of seismic rays circumscribed or near the same plane (typically over 100). Two sections of the device have been thus used with shots 8-13 and all parallel geophones located in the South. The ray paths associated to this geometry are shown in Figure 9. The inversion therefore uses six sources 
and 54 receivers, which represent 324 rays. The synchronization time between shots is not precise enough from the GPS synchronization. GPS time gives an uncertainty of $1 \mathrm{~ms}$ while $0,05 \mathrm{~ms}$ is necessary to obtain a confident tomography picture.

So, a readjustment has been made from SYTMISvel software (homogeneous model). This corresponds to a normalization of each shot. This method allows the highlighting of the precise velocity variations by cross correlation for the same shot, and synchronises the shots with the time measured on common or closer rays. The inclined plane formed by this device was sampled by a grid of $10 \times 10 \mathrm{~m}$ cells, or cells from 25 to $30 \mathrm{~m}$ wide. The inversion results are shown in Figure 9 .

\subsection{D TOMOGRAPHY RESULTS}

Data normalization and limited number of cells inversion cannot give a good quality picture of the P-wave velocity field. A map of residues on the calculated velocities shows significant errors especially in the west of the tomographic image. This image shows a structure of the velocity field that can be divided into three large units that seem to be following the horizontal direction corresponding to the stratigraphy. The first unit located near the sensors has a low velocity $(<2500 \mathrm{~m} / \mathrm{s})$ of about $50 \mathrm{~m}$ thick. The second unit is 50 to $75 \mathrm{~m}$ thick with a high velocity $(>3500 \mathrm{~m} / \mathrm{s})$. And the third unit is the most heterogeneous, with velocities of around $3000 \mathrm{~m} / \mathrm{s}$.

\section{VELOCITY ANISOTROPY ESTIMATION}

One of the objectives of the surface geophone network was to quantify the seismic velocity anisotropy. That is why the surface geophones and shots performed in mine working were designed in a rectangle. This configuration makes it possible to cover the angles variations in terms of azimuth and incident angles. More specifically, the system covers about $180^{\circ}$ in azimuth, from east to west through south, and about $60^{\circ}$ in incident angle from vertical to $25^{\circ}$ (Figure 10). These results show a moderate anisotropy with anisotropy factor of about $10 \%$ in the vertical plane and by $5 \%$ in the horizontal plane. The overall anisotropy of the overburden is a combination of both. The main directions of velocity are $\mathrm{V}_{\min }(2950 \mathrm{~m} / \mathrm{s})$ directed towards the 
South-East $\left(\mathrm{N} 170^{\circ}-230^{\circ}\right)$ with a dip of $30-40^{\circ}$, and $V_{\max }(3250 \mathrm{~m} / \mathrm{s})$ oriented along the vertical.

This moderate anisotropy is not surprising for a sedimentary cover (Oberti et al., 1979). It was also observed in the same geological context (Balland, 2008). What is more unexpected is a reversal of the main directions, usually, the maximum velocity is horizontal. In this case, the maximum velocity is vertical. This assumption is discussed in the next section ( $\$ Discussion) with all investigations on the velocity field.

\section{ANELASTIC ATTENUATION ANALYSIS: APPLIED METHOD AND RESULTS}

\subsection{METHOD USED}

The quantification of attenuation is useful to further characterize the properties and heterogeneities of the geological structure. It is also useful for the design and installation of future seismic devices at the investigation site. Anelastic attenuation is characterized by the quality factor $Q$, for $\mathrm{P}$ wave in our case, defined as the ratio between the stored energy and the energy dissipated during one wave period (Knopoff, 1964):

$$
Q=2 \pi \frac{E_{0}}{\Delta E}
$$

where $\mathrm{E}_{0}$ is the maximum energy (amplitude of energy) and $\Delta \mathrm{E}$ is the energy dissipated during a wave period. Note that the higher the $\mathcal{Q}$ value, the less energy is lost, and therefore the anelastic attenuation is low and $\Delta \mathrm{E}$ is frequency dependent. Several methods are available to calculate the $Q$ value, both in the temporal and in the frequency domains. We used the classical spectral amplitude ratio method based on the equation given by (Toksoz et al., 1979; Sain et al., 2009):

$$
\ln \left(\frac{\left|X_{2}(f)\right|}{\left|X_{1}(f)\right|}\right)=K-\frac{\pi \cdot \Delta t}{Q} \cdot f
$$

where $X_{1}(f)$ and $X_{2}(f)$ are the spectrum amplitude of signal 1 and $2, \Delta t$ is the time difference between the first arrival of the signal 1 and 2 and $\mathrm{K}$ is a constant, independent of the frequency. 
Equation (2) calculates the $\mathcal{Q}$ value by estimating the slope of the amplitude ratio as a function of frequency. The frequency band of interest was found with $10-250 \mathrm{~Hz}$ (Figure 11).

The spectral amplitude ratio was considered for collinear seismic rays of $\mathrm{P}$ waves with quasi vertical incidence angles emitted by weight drops of $500 \mathrm{~kg}$, located just below the Lilas station (CBL5, CBL6 and CBL7 on Figure 6). As a result, the estimated $Q$ factor characterize the sedimentary units located in between the seismic stations, which are separated by $\sim 40$ meters. The advantage of this approach is to avoid the correction of source radiation pattern and to estimate the loss of frequency content on the same ray path (Toksöz et al., 1979; Picotti and Carcione, 2006). Moreover, very precise $\mathrm{P}$ wave velocity estimates (a prerequisite for $Q$ factor calculation) could be done by taking advantage of very similar P wave forms (see below).

In practice, generally the $\mathrm{Z}$ components of the of the 1-D and 3-D sensors have been used. For P-waves phase arrival isolation, a Hanning window of $0.2 \mathrm{~s}$ has been applied to the first phase picked. No frequency filtering was applied to the data. The quality factor was then calculated using:

$$
Q=\pi \frac{\Delta r}{\mu V_{p}}
$$

with $\Delta \mathrm{r}$, being the distance between the drop weight and the sensor; $\mathrm{V}_{\mathrm{p}}, \mathrm{P}$ wave velocities, are estimated by cross-correlation between $1 \mathrm{DZ}$ and $3 \mathrm{DZ}$ seismic traces and $\mu$, the slope of spectral ratio. Note that the experiment was not especially designed for the attenuation characterisation.

\begin{tabular}{|c|c|c|c|c|}
\hline Date & Id & $\begin{array}{c}\text { distance from 3DZ-Lilas } \\
\text { sensor }(\mathrm{m})\end{array}$ & $\begin{array}{c}\text { distance from 1DZ-Lilas } \\
\text { sensor }(\mathrm{m})\end{array}$ & Velocity (m/s) \\
\hline 30/09/2010 11:00 & CBL5 & 110,5 & 149,5 & 2928,6 \\
\hline 30/09/2010 11:12 & CBL6 & 104,1 & 144,8 & 2827,6 \\
$30 / 09 / 201011: 14$ & CBL6b & 104,1 & 144,8 & 2827,6 \\
\hline 30/09/2010 11:23 & CBL7 & 106,4 & 146,3 & 2827,2 \\
\hline 30/09/2010 11:27 & CBL7b & & 146,3 & 2827,6 \\
\hline
\end{tabular}

Table 3 : summary of distances between weight drops and sensors, and velocities calculated from cross-correlation between 1DZ and 3DZ seismic traces. 


\subsection{RESULTS OF THE ATTENUATION ANALYSIS}

Signal spectrums of 1DZ and 3DZ seismic sensors of the Lilas station, as well as associated spectrum ratios of weight drops carried out below Lilas station, are showed on Figure 11. Spectral ratios are quite noisy (Figure 11-b and d), nevertheless those calculated from the P-wave arrival times are smoother (Figure 11-d). These spectral ratios show a weak increase of the slope until $250 \mathrm{~Hz}$, and then a decrease. This tendency is clearly visible on the mean spectrum.

Several linear regression fittings were tested on spectral ratios in a frequency range between 0 and $250 \mathrm{~Hz}$. From these tests, we observe weak Q factor values. These values are ranging between 5 and 15, because of the data variability (Figure 11-b and d). Values greater than 20 are likely not possible despite this variability. Thus, the $\mathrm{Q}$ factor for this site can be reasonably estimated at $\mathrm{Q}=15 \pm 5$ on a frequency band ranging between 10 and $250 \mathrm{~Hz}$.

These calculations confirm that the anelastic attenuation is significant on the site despite $\mathrm{P}$ wave velocities in the order of magnitude of $2900 \mathrm{~m} / \mathrm{s}$. Note that velocities are less sensitive to medium fracturing than the Q factor (Sjogren et al., 1979; Barton, 2007).

\section{DETECTABILITY : ANALYSIS AND RESULTS}

Blasts $5 \mathrm{a}(1 \mathrm{~kg})$ and $5 \mathrm{~b}(300 \mathrm{~g})$ were carried out at the same hypocentral distance from Lilas and Groseilliers stations, $237 \mathrm{~m}$ and $236 \mathrm{~m}$ respectively. These shots were made specifically to easily compare the responses of the two probes. The response of the sensors in terms of amplitude shows no significant difference (Figure 12). 3D Groseilliers probe therefore shows the same response than the Lilas 3D sensor for the same solicitation. Moreover, those very close responses show that the probes are identically coupled to the ground.

To test the capacity of the network in terms of detectability, blasts with different incremental charges have been carried out, as blast number 8 with charges from $100 \mathrm{~g}, 200 \mathrm{~g}$ to $500 \mathrm{~g}$ (Figure 13). These shots are located at $185 \mathrm{~m}$ from the Lilas station and $250 \mathrm{~m}$ from the Groseilliers station. Blast 8 at $100 \mathrm{~g}$ is below the trigger thresholds set at $6.510^{-7} \mathrm{~m} / \mathrm{s}$ on $3 \mathrm{D}$ probes of the permanent monitoring system. However, this signal is visible, i.e. out of the noise $\left(210^{-7} \mathrm{~m} / \mathrm{s}\right)$, on 
the continuous recording of Lilas station, but is not visible on the Groseilliers continuous recording (Figure 13-a). We observe that a charge of $200 \mathrm{~g}$ was detected at $185 \mathrm{~m}$ from the Lilas station, while at the same distance a charge of $100 \mathrm{~g}$ is not detected, but visible.

A series of 10 drops of a block of $500 \mathrm{~kg}$ was carried out in the Louise Gallery. Nine of these drops were recorded by Lilas station. Only one drop was not detected, the farthest located at $\sim 180 \mathrm{~m}$ from the Lilas station, where the block was dropped into the water. None of these block drops were detected by 3D Groseilliers and Puits-Armand stations. The farthest drop block detected was located at $165 \mathrm{~m}$ from the 3D sensor Lilas. The recorded peak particle velocity was $\sim 2.10^{-6} \mathrm{~m} / \mathrm{s}$

\section{DISCUSSION}

\subsection{VELOCITY FIELD AND ORIGIN OF THE PERTURBATIONS}

The first method of velocity estimation of the geological layers (Table 4) clearly shows a first $30 \mathrm{~m}$ thick low velocity layer of $1900 \mathrm{~m} / \mathrm{s}$, which is located over a $90 \mathrm{~m}$ thick layer of $3100 \mathrm{~m} / \mathrm{s}$. The third layer is $30 \mathrm{~m}$ thick with a higher velocity of $3700 \mathrm{~m} / \mathrm{s}$. The ore layer shows a velocity of $\sim 3400 \mathrm{~m} / \mathrm{s}$. The first layer can be associated to both the altered layer and alternating marllimestone while the second can be associated to the Bajocian limestone. Finally, the third layer is associated to marls of Charennes. Note that the velocity measurements integrate layers of smaller thickness as the layer of marl $(19 \mathrm{~m})$ located between two limestones, which give an idea of the limitations of the methods to estimate the seismic velocity in this context. Velocity observations are rather consistent with what has been observed at other sites of iron basin (Tastet et al., 2007; Contrucci et al., 2010).

\begin{tabular}{|c|c|c|c|c|c|}
\hline \multicolumn{2}{|c|}{ Site } & $\begin{array}{c}\text { Surface } \\
\text { layer }\end{array}$ & $\begin{array}{c}\text { Bajocien } \\
\text { limestones }\end{array}$ & $\begin{array}{c}\text { marl of } \\
\text { Charennes } \\
\text { layer }\end{array}$ & $\begin{array}{c}\text { Iron } \\
- \text { ore } \\
\text { layer }\end{array}$ \\
\hline \multirow{2}{*}{$\begin{array}{c}\text { 4 layers } \\
\text { model }\end{array}$} & thickness (m) & 27 & 89 & 33 & 40 \\
\cline { 2 - 6 } & \begin{tabular}{c} 
velocity (m/s) \\
\cline { 2 - 6 } \\
Uncertainty \\
$(\mathrm{m} / \mathrm{s})$
\end{tabular} & 1867 & 3137 & 3695 & 3398 \\
\hline
\end{tabular}

Table 4 : summary of the velocity characteristics of the $\mathrm{P}$ wave velocity model on site. 
The anisotropic velocity measurements show a remarkable velocity increase with the dip (Figure 9). Usually, sedimentary interfaces show an inverse anisotropy direction (Oberti et al., 1979), indeed waves propagate faster in the horizontal plane of the layers and more slowly perpendicularly through the layers. Lowest velocities are observed at a dip of about $35^{\circ}$ associated with azimuths at around $220^{\circ}$ (Figure 9). As for other sites (Ikeda et al., 1981), the origin of this anisotropy is likely to be related with the presence of faults. The NE-SW faults orientation observed underground in the mine (Figure 6) coincides with the velocity anisotropy field. The most reasonable explanation, taking into account geological features of the area, is that waves which propagate in the fault plane axis cross "crushed" areas with lower mechanical properties and lower velocities. The influence of faults can also explain the anisotropy inversion due to the superimposition of sedimentary layers. Without the presence of faults on the site, we would probably measure horizontal anisotropy usually observed in a sedimentary terrain.

\subsection{ATTENUATION FIELD AND DETECTABILITY}

The environment of the Groseilliers station has no particularly significant attenuation compared to the Lilas station. This observation is confirmed by the record of an equidistant blast to both stations with maximum amplitude almost identical on both 3 components probes (Figure 12).

The minimum explosive source detected by the probes is less than $200 \mathrm{~g}$ of explosive at $250 \mathrm{~m}$ from a 3 components probe. On the other hand, rockfall on the floor in the gallery Louise (500 $\mathrm{kg}$ dropped from $2 \mathrm{~m}$ ) were detected by Lilas station and this, regardless of the hypocentral distance (up to $150 \mathrm{~m}$ ). Transmission of waves generated by rockfalls is probably advantaged by the strong low-frequency content of the source. The rockfall efficiency, in terms of wave propagation, must also be better than explosive. Indeed, a significant amount of explosive charge is converted into heat and plastic deformation.

The anelastic attenuation is significant on the site, with a $Q$ factor estimated at $15 \pm 5$ in the frequency band ranging between 10 and $250 \mathrm{~Hz}$ for $\mathrm{P}$ wave. This important anelastic attenuation is probably related to the faulting observed on the site. That reduces the capacity of a network to 
detect small microseismic events, with a moment magnitude below $-0,4$ at around 300 meters, expected during the initiation of a subsidence and/or collapse. Indeed, the strongest seismic event of $\mathrm{Mw}=-0,45$ in august 2011 was not clearly detected by Lilas station. This confirm the strong attenuation of the site.

Note that in the literature we can observe low Q value factors for velocities between 3000 and $4500 \mathrm{~m} / \mathrm{s}$, when the overburden is faulted and fractured (Barton, 2007). Velocities are less sensitive to fracturing of the medium than the $\mathrm{Q}$ factor. Indeed, on a site located in similar geological formation (Cerville-Bussoncourt, France), where an underground cavity collapse was triggered, it has been observed that a $10 \%$ velocity change can correspond to a 50 to $70 \%$ variation of the Q factor value (Marot et al., 2014; Kinscher, 2015).

\subsection{LACK OF SEISMIC PRECURSORS AND UNDERGROUND FAILURE PROCESSES}

The low level of seismic signals detected by the Groseilliers station during the subsidence seems to be mainly due to the high seismic attenuation of the site, as shown by this study, as the possibility of a sensor failure is excluded. However, this attenuation phenomenon is likely coupled with very weak seismic sources and/or with very low frequency $(<10 \mathrm{~Hz})$. In addition, the collapsed pillars were not probably healthy and may have already been damaged by the old total pillar removal area nearby (robbed pillar area, Figure 14). Moreover the flooding of the area since 2007 has certainly weakened the existing mine workings, because water accelerates crack propagation and thus increases rock damages (GISOS, 2007).

In addition, the uncertainty of the underground galleries positions relatively to the surface, allows considering a location of the maximum surface subsidence from 10 to $30 \mathrm{~m}$ further south. This observation could move the collapsed zone in the robbed pillar area, at the border of the healthy gallery. Then, pillars involved in the collapse would have been already damaged by total pillar removal operations, and pillars located nearby have been also fractured. Then the seismogenic (energetic) fracture has probably occurred prior the installation of the Groseilliers station. We can therefore consider the hypothesis of damaged pillars before the collapse of November 2009. The 
formation of fractures and/or microcracking in the volume of the pillar would produce a rheology capable of inhibiting large, fast and energetic seismic ruptures. This rheology only would allow slow transient deformation (aseismic slip on fracture planes, and or plastic behavior in the volume), possibly with small seismogenic ruptures, infra-metric, so too weak to be recorded by the Groseilliers station.

Moreover, secondary faults, to the main fault, have been identified in mine workings at the N-W and S-W below the Groseilliers stations (Figure 2, Figure 6, Figure 14). These faults may have been remobilized during robbed pillar operation of the exploitation located at the SW of the Groseilliers station. This damage zone may also prevent the transmission of the seismic wave generated by subsidence.

Furthermore, the analysis of the detected microsismic event show small dimension of the fracture. Dimension of the source are between $\sim 10 \mathrm{~m}$ and $\sim 70 \mathrm{~m}$, with a mean of $20 \mathrm{~m}$. These dimensions are in agreement with the low moment magnitude detected during the subsidence, even in the acceleration period. During this period, if strong events had occurred they would have been detected.

Therefore the subsidence occurred in areas that already had low mechanical properties due to the robbed pillar extraction method or located inside the area, aggravated by flooding. In addition, many faults have been observed on the site. This causes strong anelastic seismic attenuation, which is not favourable for seismic signal transmission.

\section{CONCLUSIONS}

This study has highlighted significant anelastic attenuation on the site. This important anelastic attenuation is probably related to the extensive faults system that intersects the overburden. Moreover, robbed pillar extraction and flooding of the site have induced a reduction of the mechanical properties of the overburden. It probably explains the low level of detection of small microseismic events related to the collapse, measured by surface levelling. It reflects a poor transmission of microseismic waves, added to a slow kinetics subsidence mechanism with little 
seismic energy release. Indeed, subsidence, which began probably in early 2009, showed an almost linear regime between November 2009 and January 2011, with constant vertical displacement velocities. The maximum vertical velocity of $2 \mathrm{~cm} /$ month was reached during more than 12 months, indicating a slow and steady strain energy release. Moreover, we observe that when the rate of subsidence increased between May and November 2011, with $10 \mathrm{~cm} /$ month in September 2011, the number of detected events has also increased. If, as it was the case for the collapses of Auboue 1996 and of Moutiers 1997 for example, where most of the strain energy (about 70 to $80 \%$ ) was released in a few weeks, with a significant subsidence in a few hours to a few days, more microseismic events would normally have been recorded. It is therefore very likely that the failure mechanism of the mine workings, causing the subsidence, is also both very slow and regular.

The microseismic monitoring network in place is more appropriate for the detection of rapid subsidence mechanisms. Like the seismological monitoring, based on both seismic networks for earthquakes and geodetic networks for large movements slow and aseismic, it is possible to conduct ongoing monitoring by geodesic method.

\section{Acknowledgments :}

This work was undertaken with the financial support of the French Geological Survey (BRGMDPSM) upon request of the Regional Direction of Environment, Land Settlement and Housing (DREAL) and the Public Interest Group for support and expert studies (GEODERIS). We thank BRGM-DPSM for making available the technical and human resources involved, without which this large-scale scientific experiment could not have taken place. The authors also thank GEODERIS for their collaboration. 
Figures

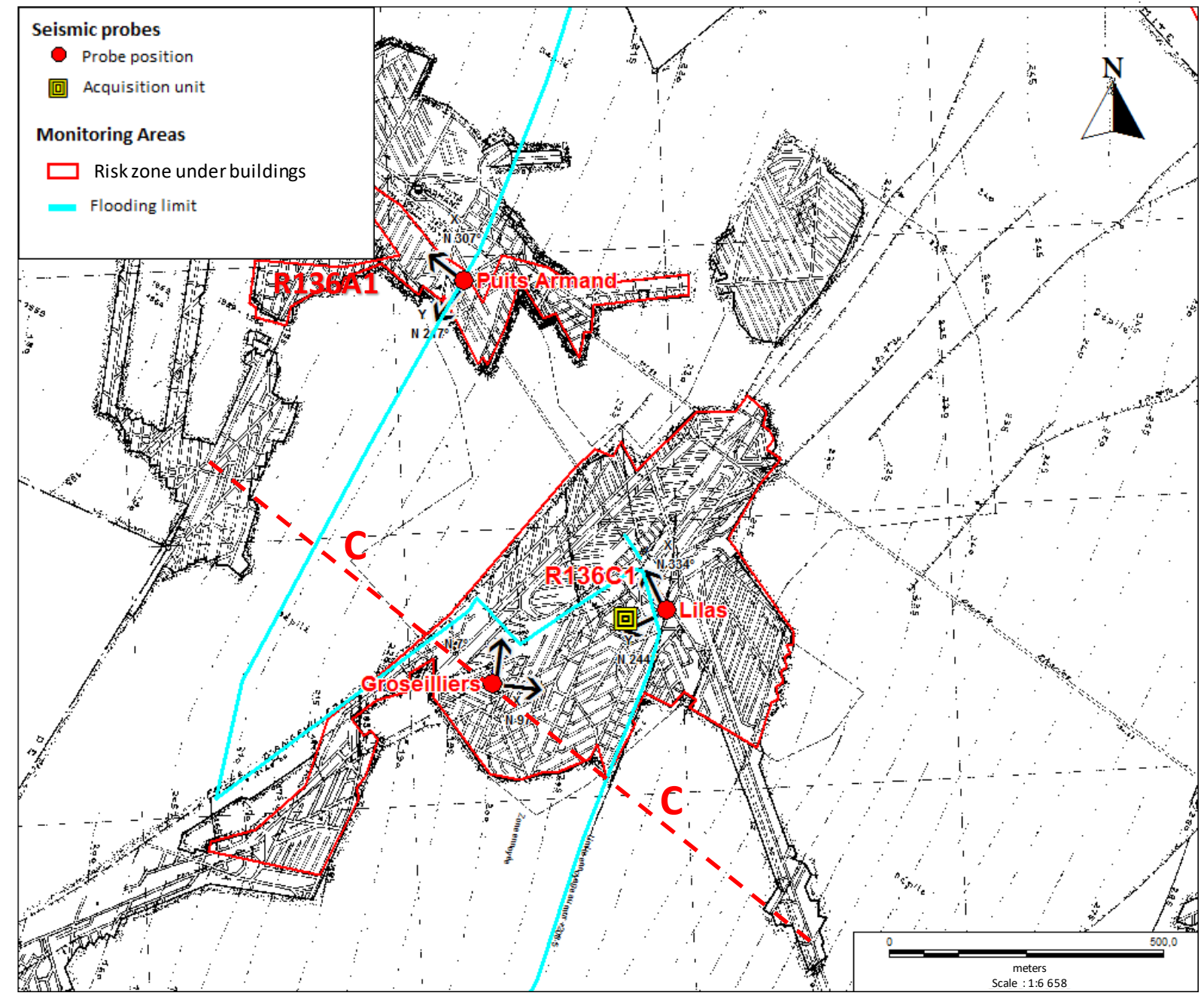

Figure $1:$ mine workings of the iron ore gray layer of the site and location of the risk zone (red lines) and the permanent microseismic network (red points). 


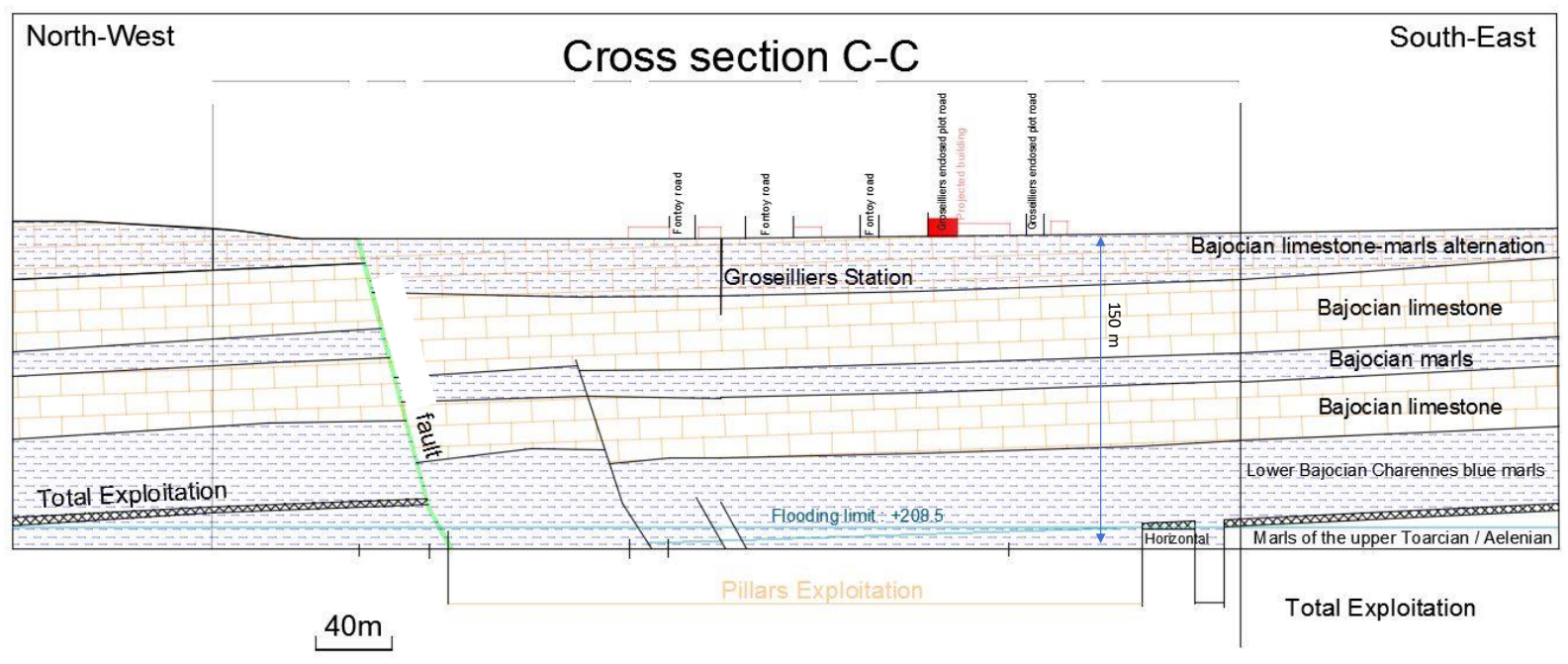

Figure 2: Geological cross section at the Groseilliers microseismic station, from BRGM. 


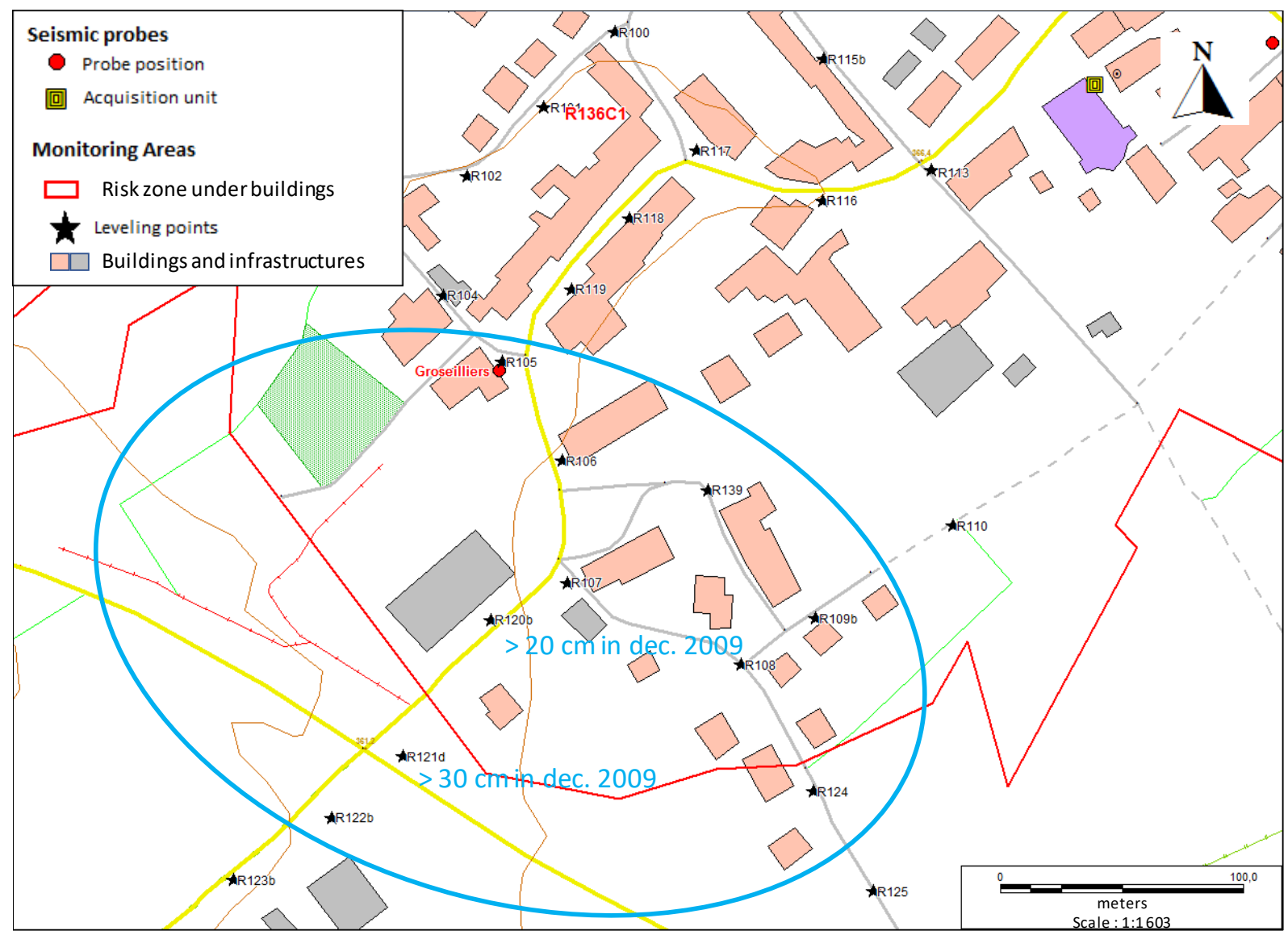

Figure 3 : zoom on the subsided zone and location of the leveling points. Red line marks the limit of the risk zone, yellow line represents the extension of the surface subsidence (GEODERIS). 


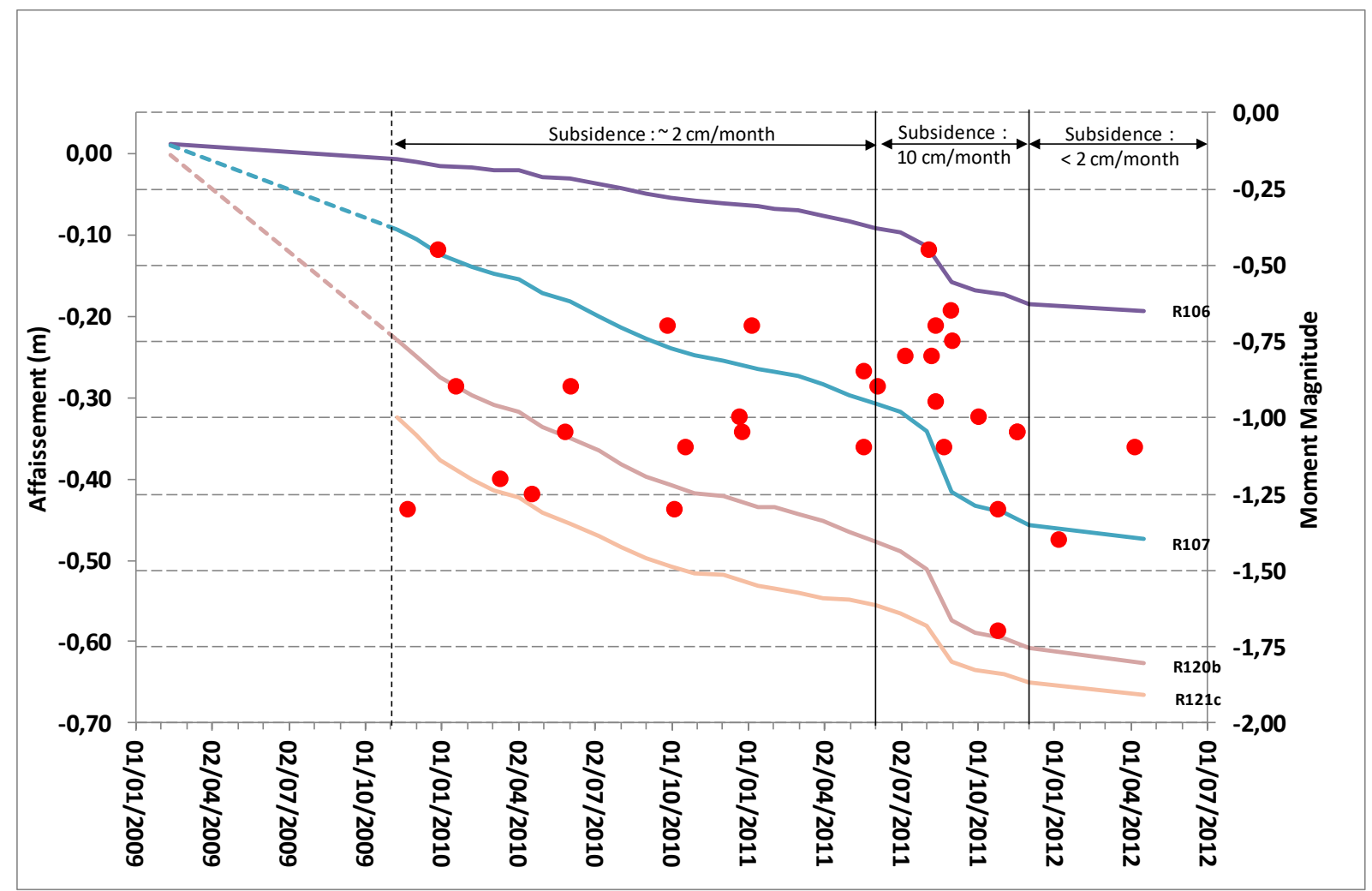

Figure 4 : leveling measurements since January 2009 until August 2012 (BRGM-DPSM) of the points located in figure 3. Red point represents the moment magnitude of the microseismic events recoded during the period. 


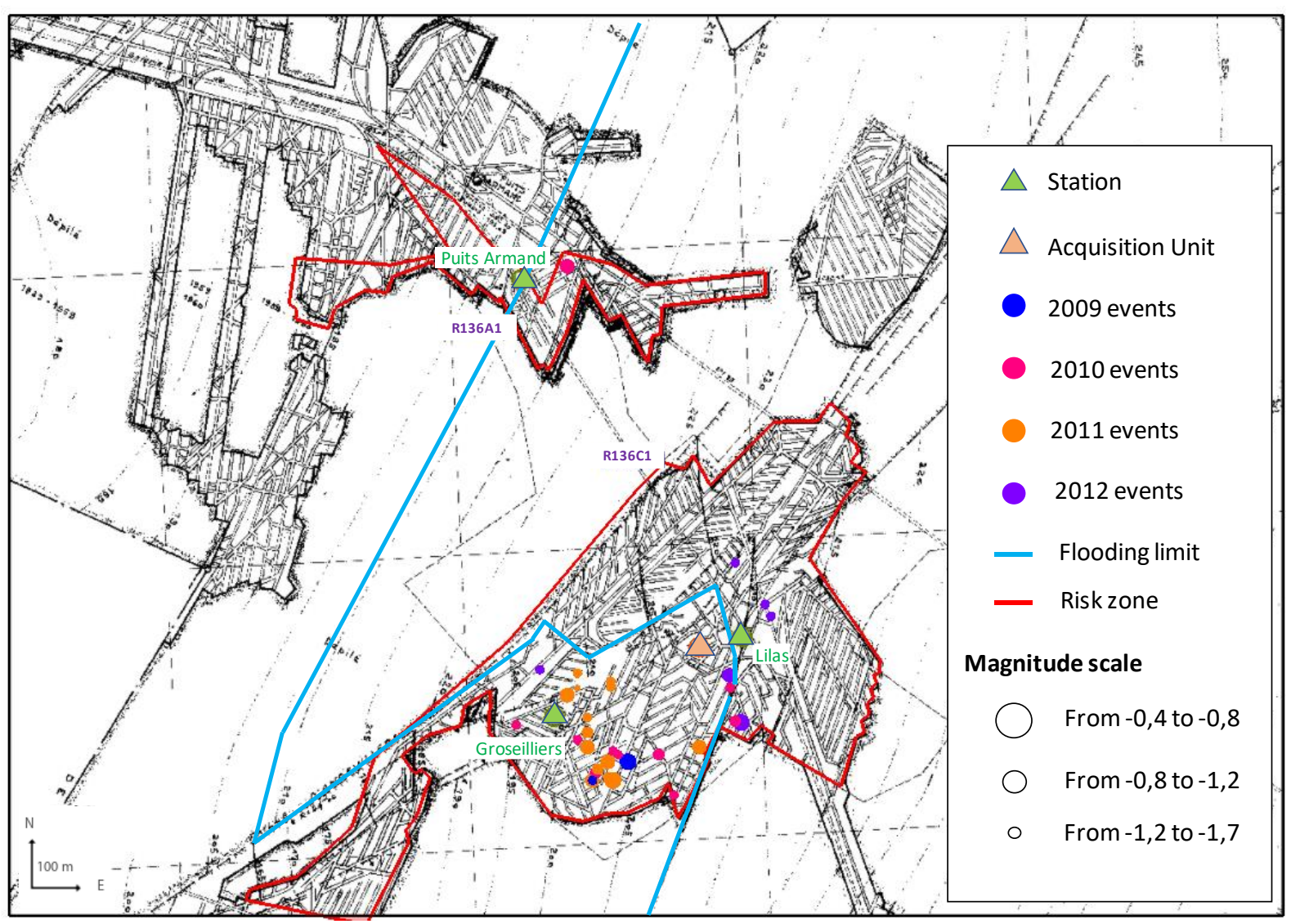

Figure 5 : location of the microseismic activity on the site superimposed to the grey layer mine workings, the permanent microseismic network, the flooding limit and the subsided area. 


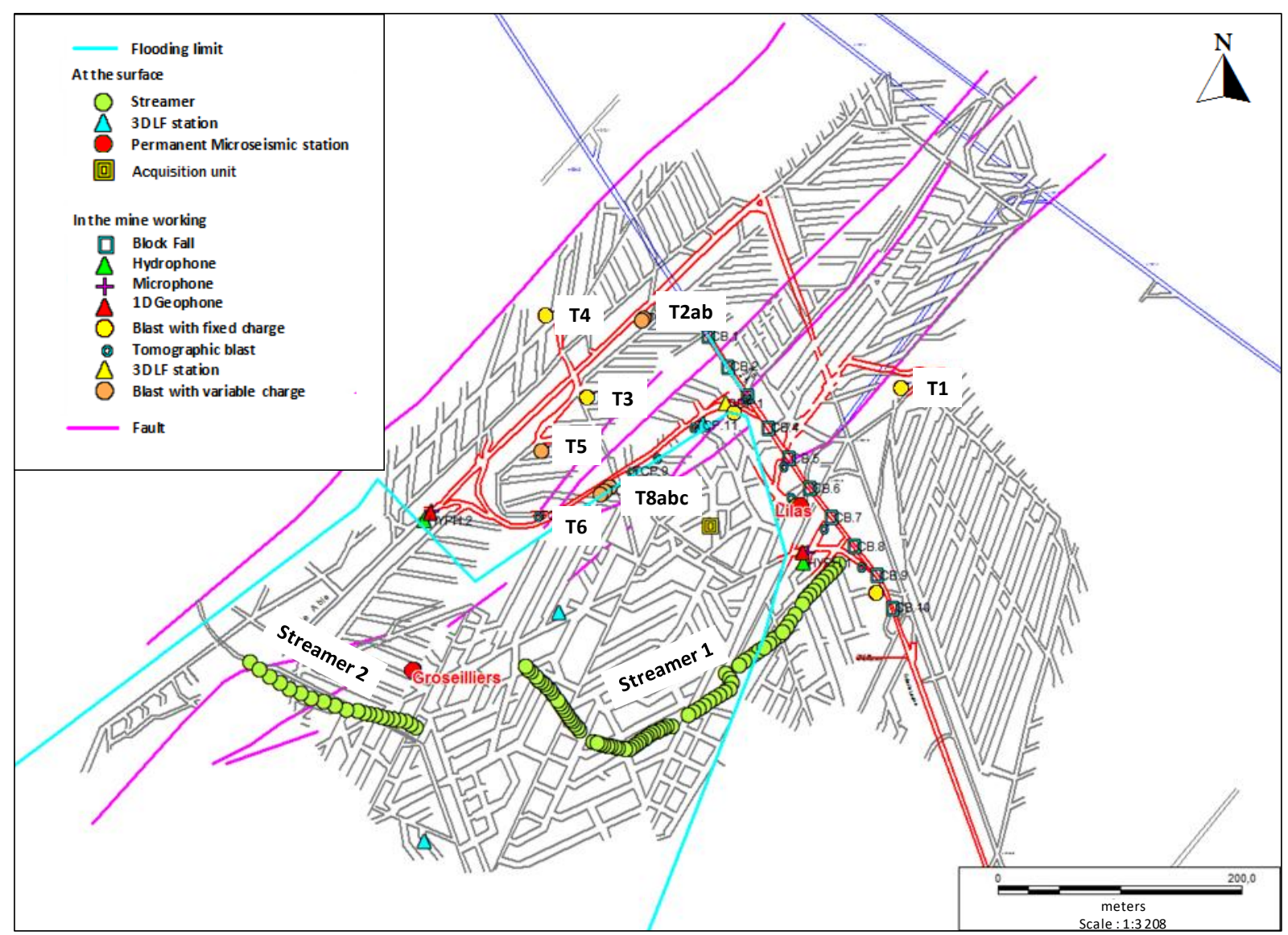

Figure 6: Location of the different acquisition system and the blast superimposed to the grey layer mine workings (BRGM-DPSM). 
a)

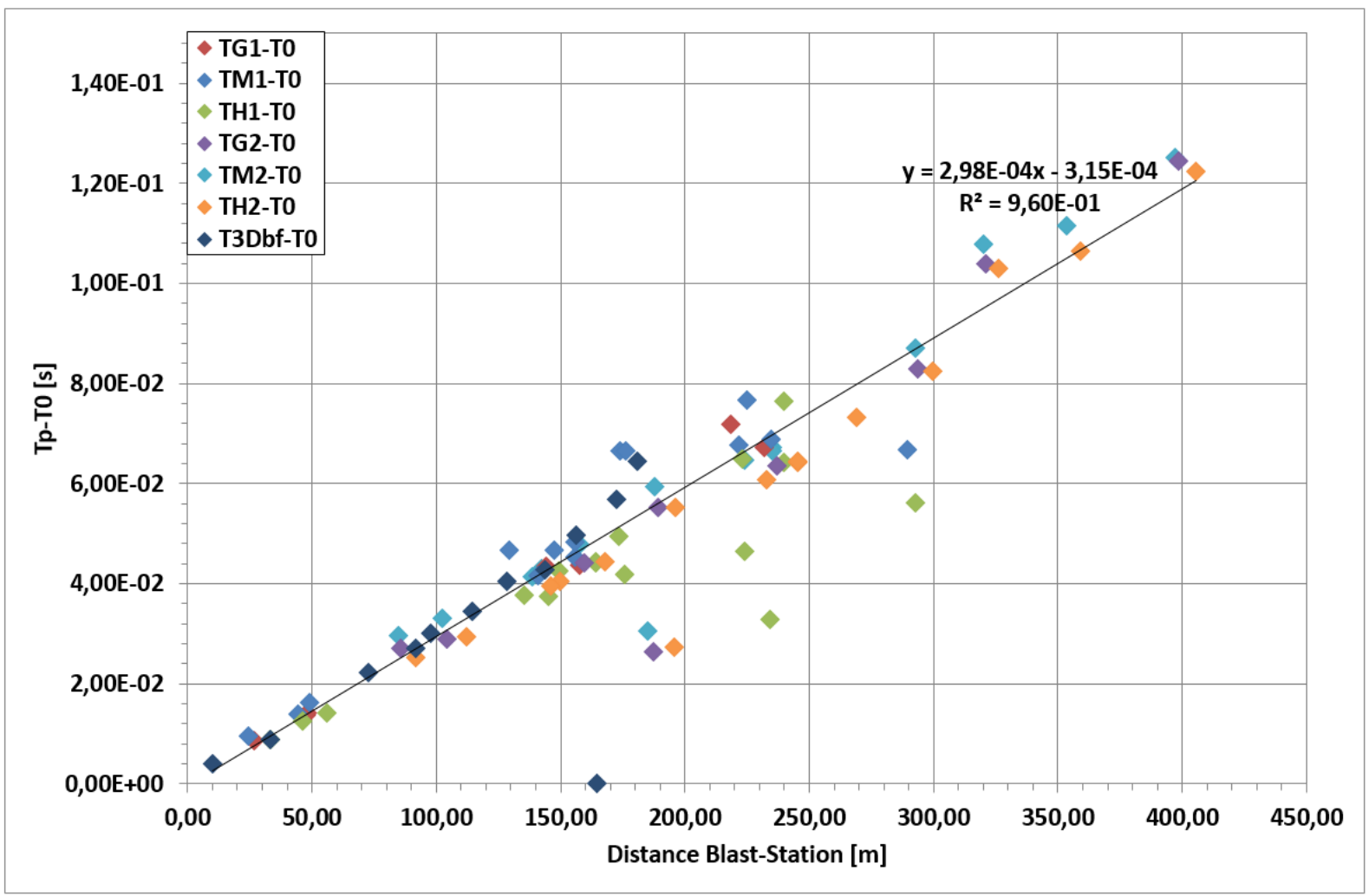

b)

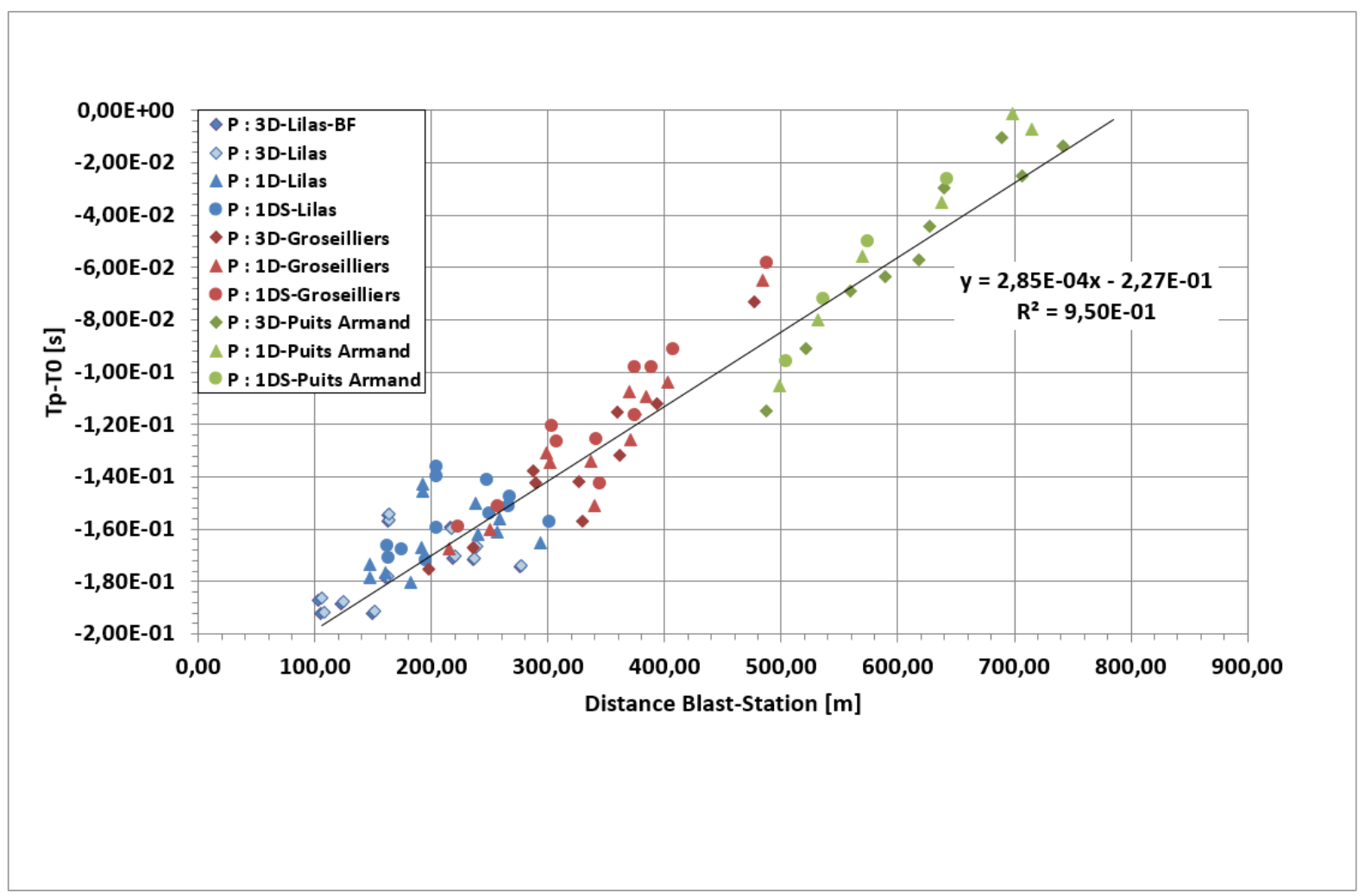




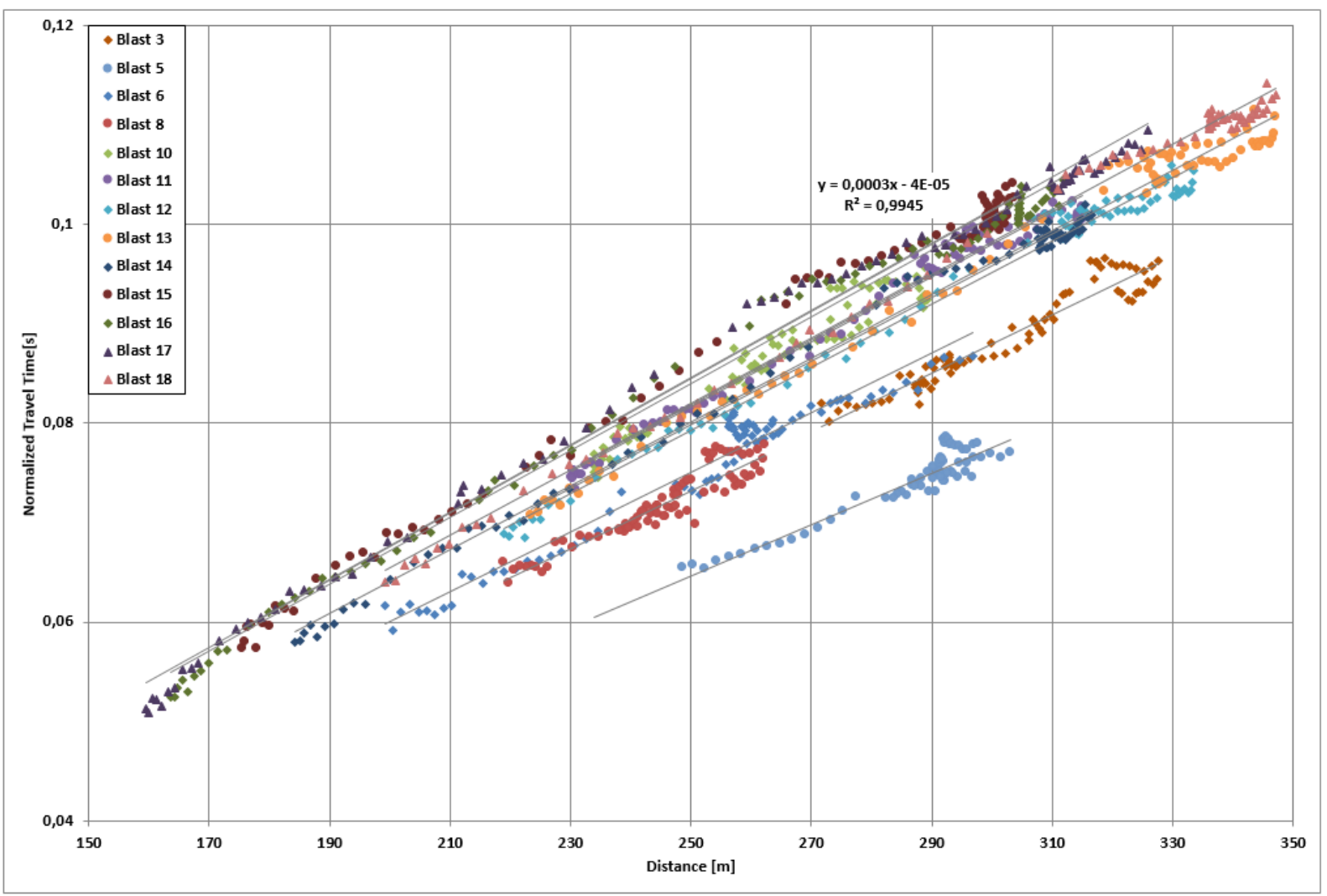

Figure 7 : time-distance graph a) from acquisition system located at the bottom of the mine, b) from the permanent microseismic network and c) from the temporary streamer 1 located at the surface. 
a)

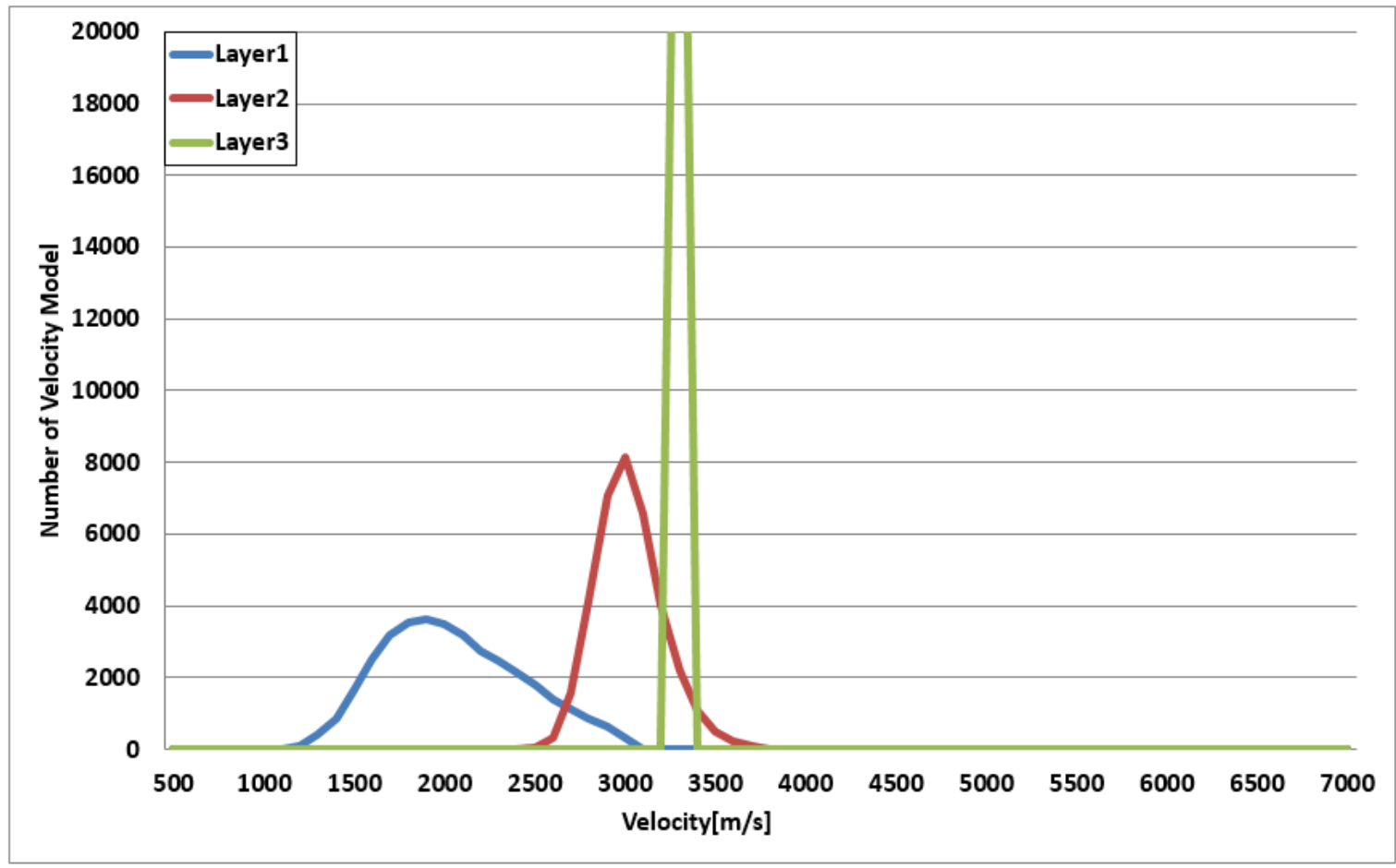

b)

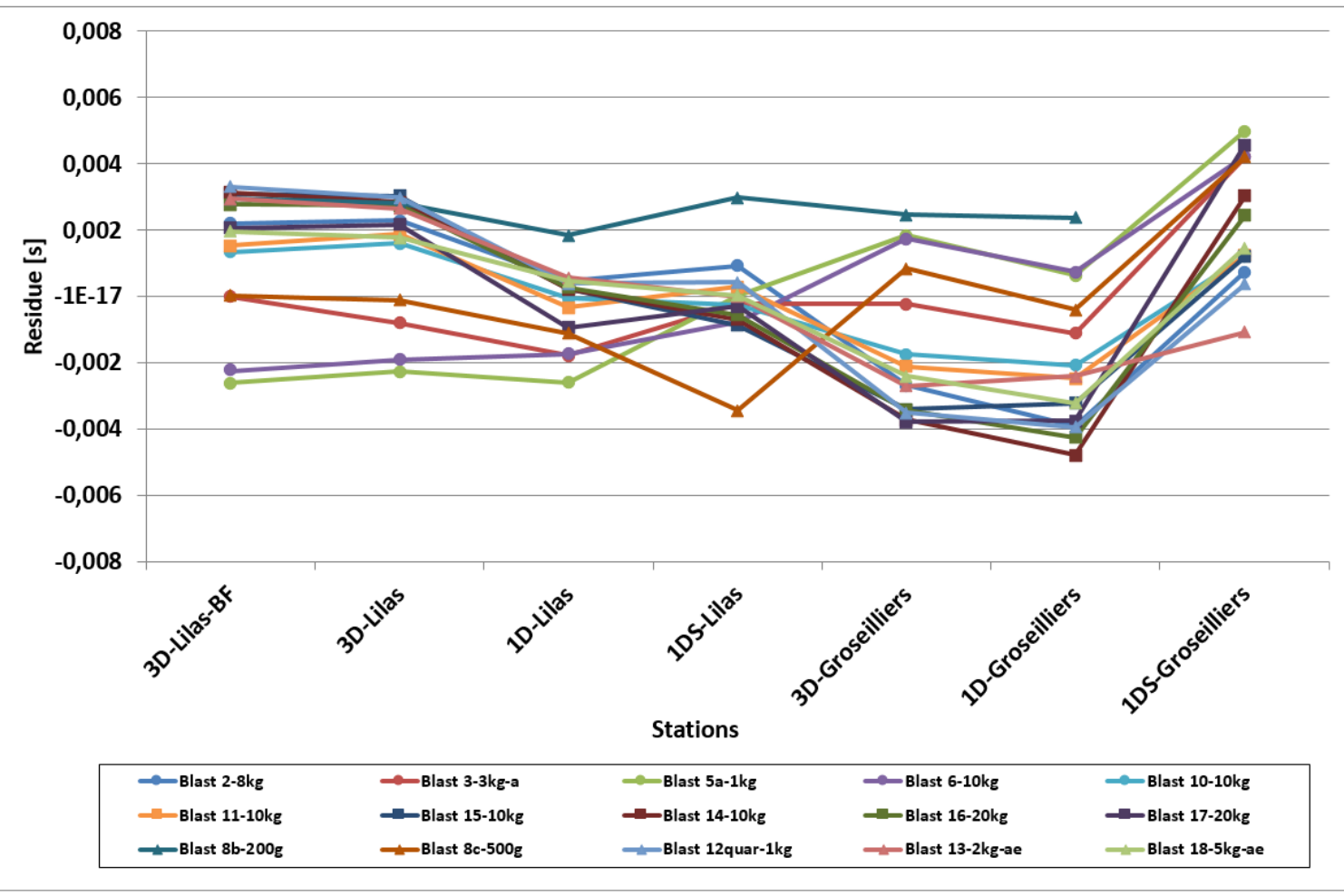




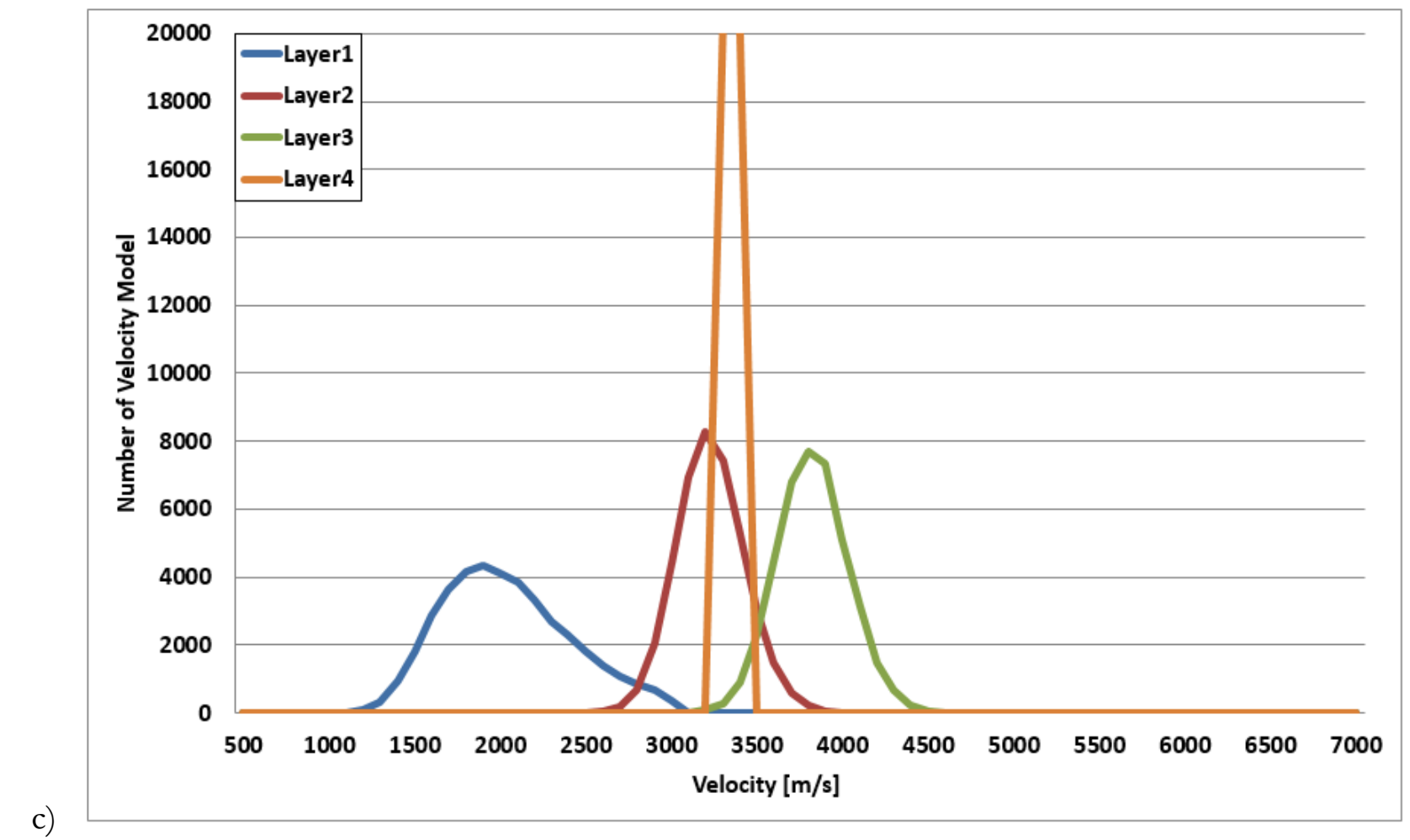

c)

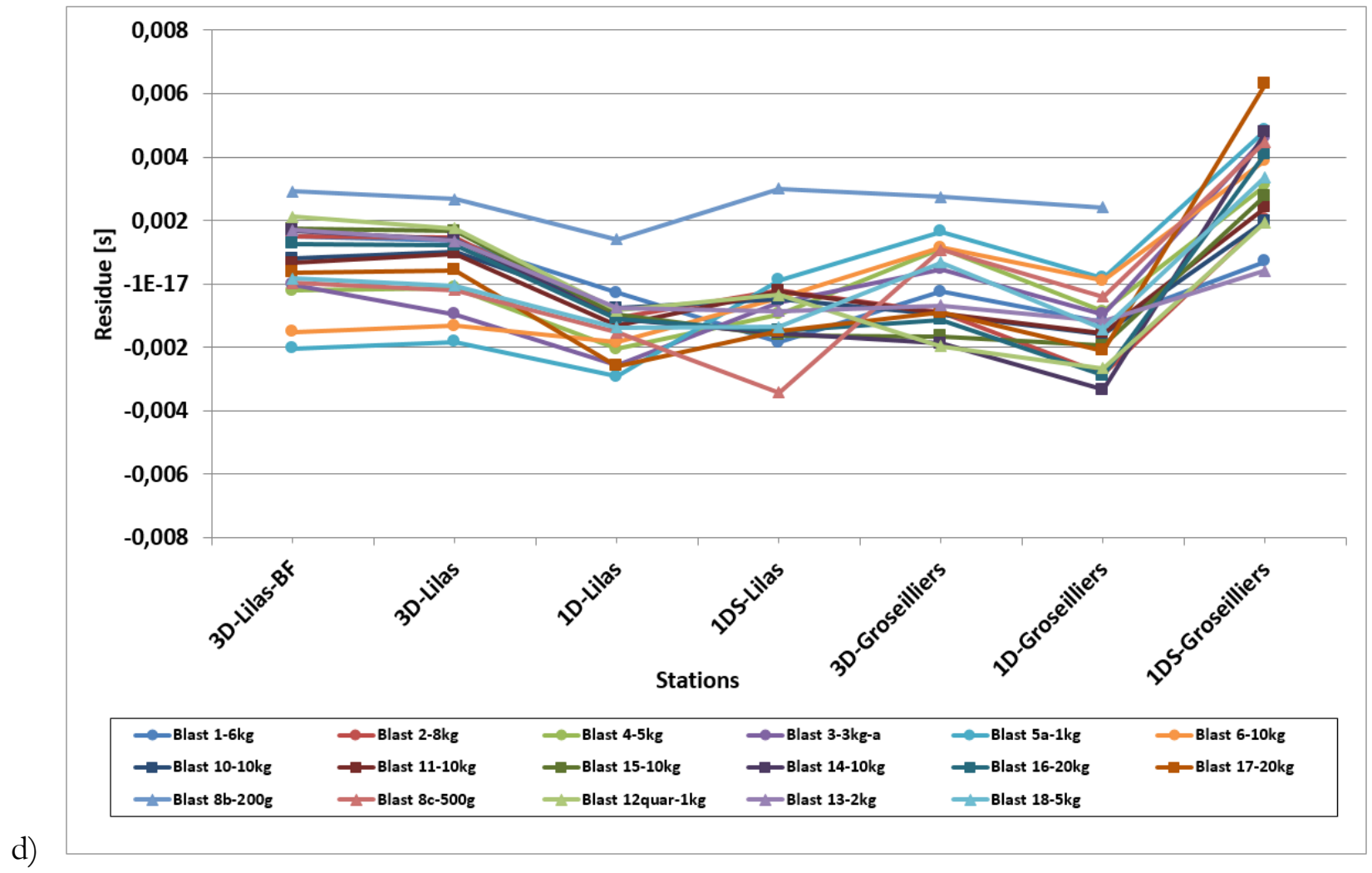

Figure $8: 1 \mathrm{D}$ velocity distribution for inversions performed with a model a) with 3 layers and $\mathrm{b}$ ) the associated time residues. 1D velocity distribution for inversions performed with a model c) with 4 layers and d) the associated time residues. 

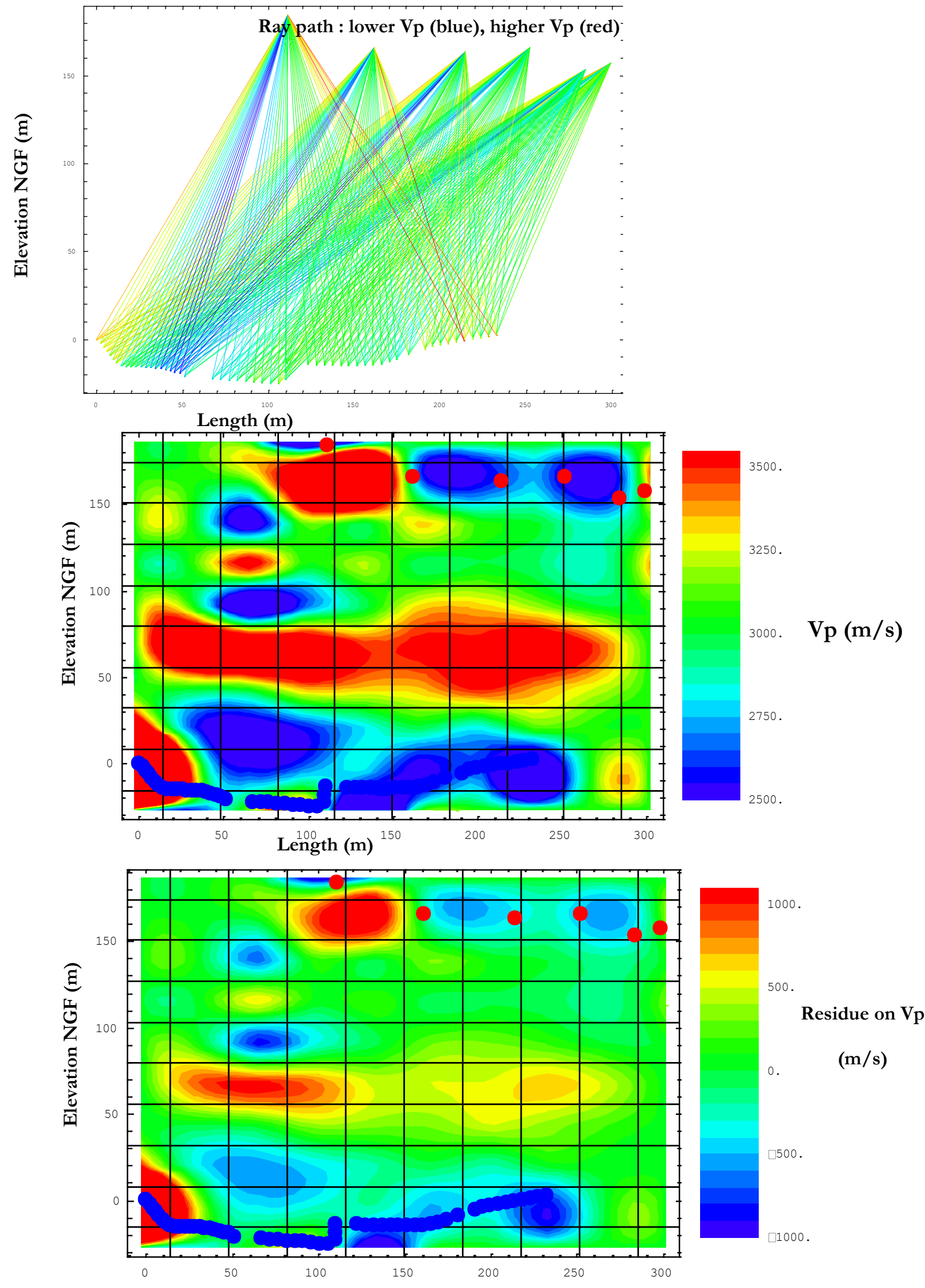
Figure 9: a) 2D seismic ray coverage of the tomographic plan located between shots and streamer 1. b) tomographic inversion and c) associated residues. Red points represent the location of the blast and blue points the location of the streamer sensors. 

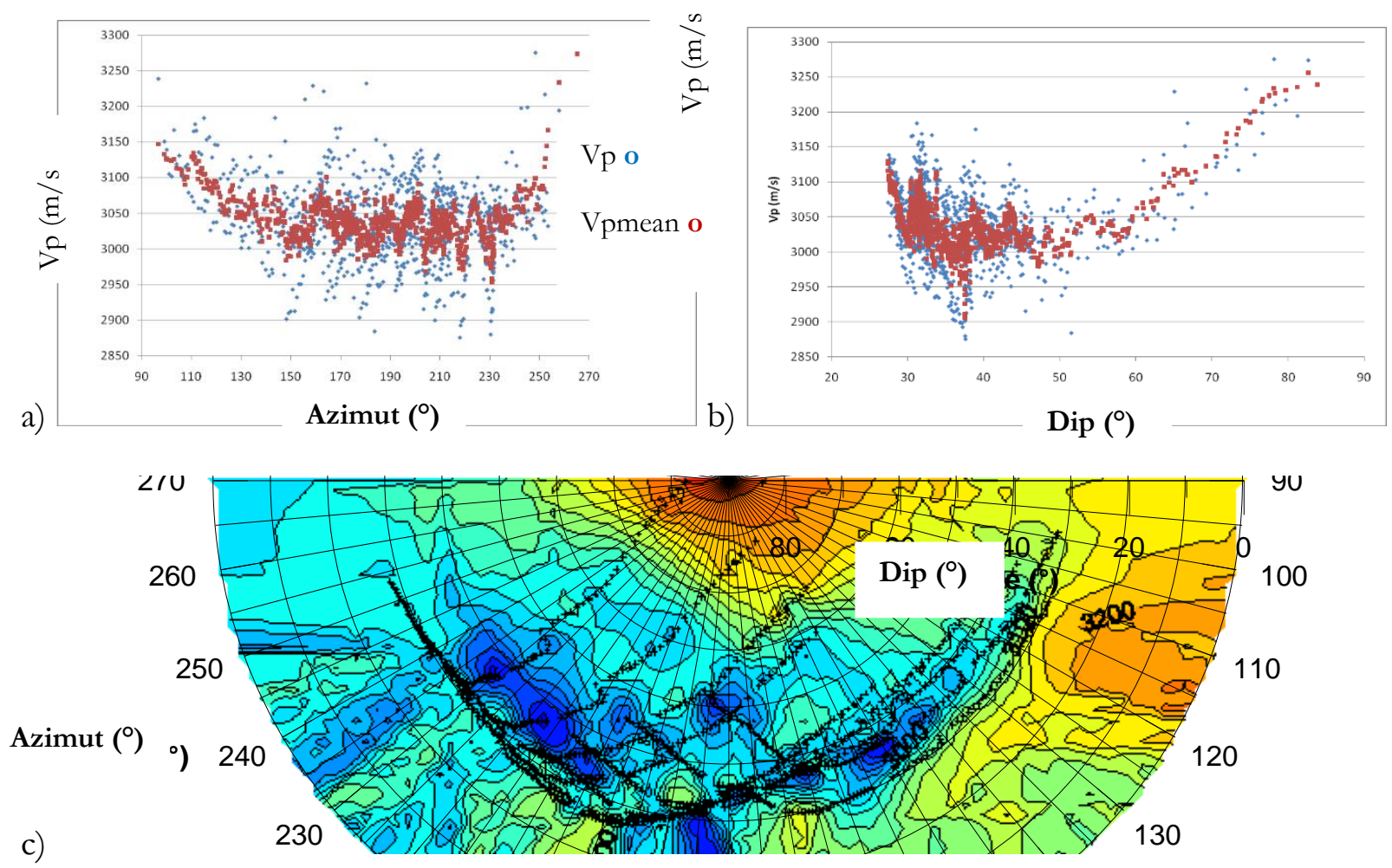

Figure 10:2D velocity distribution of $\mathrm{P}$ wave as a function of a) azimuth, b) dip and c) stereographic graph. 


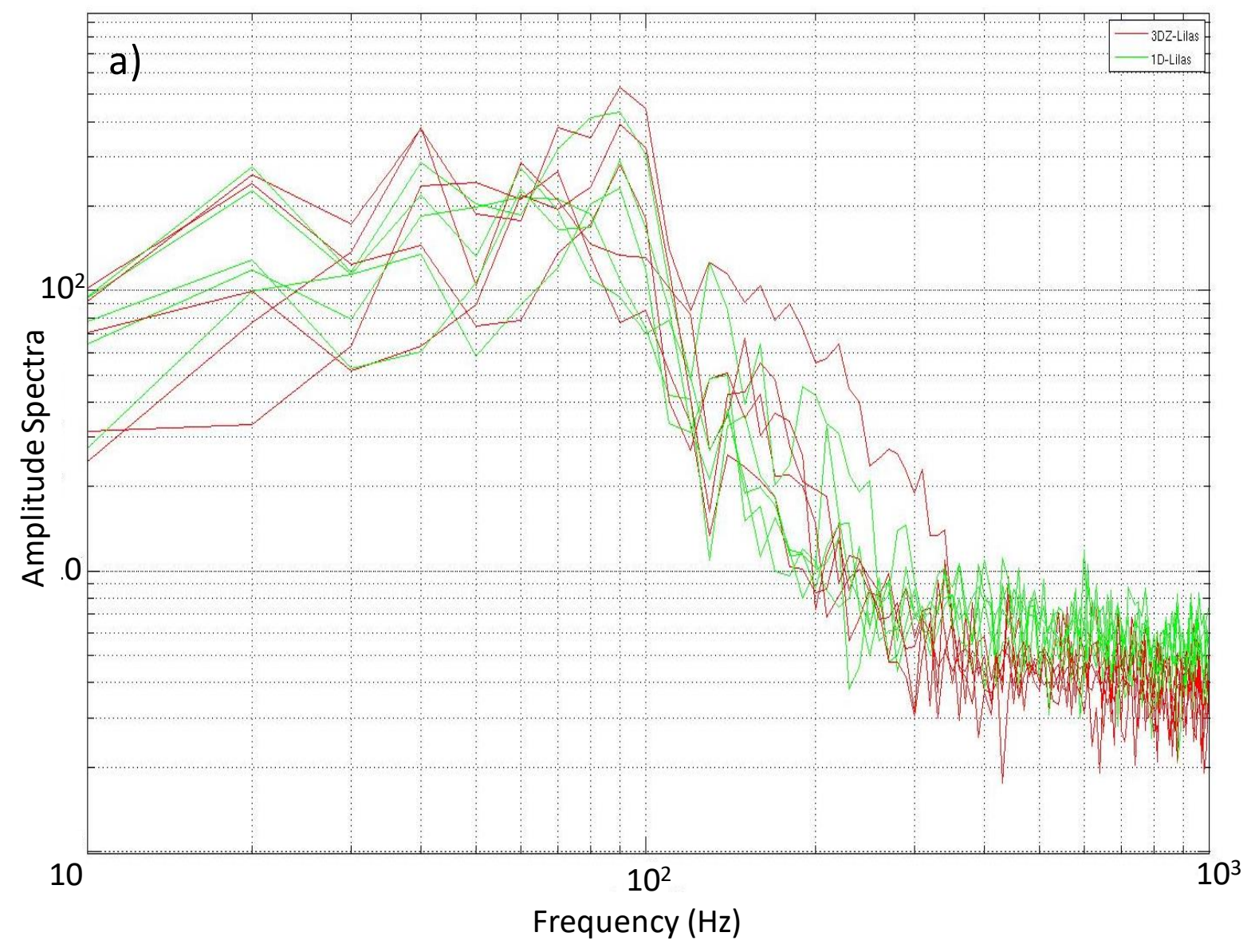




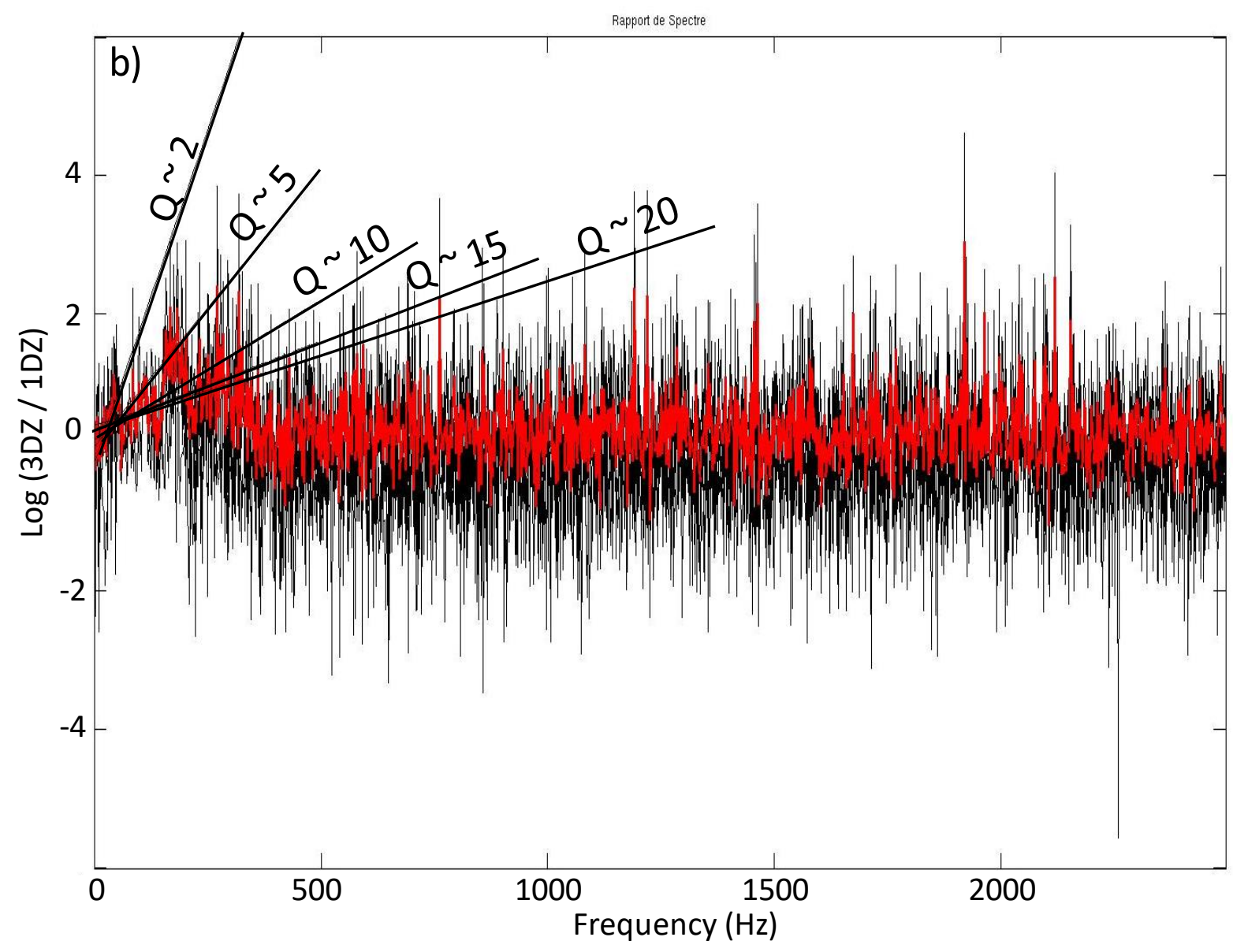




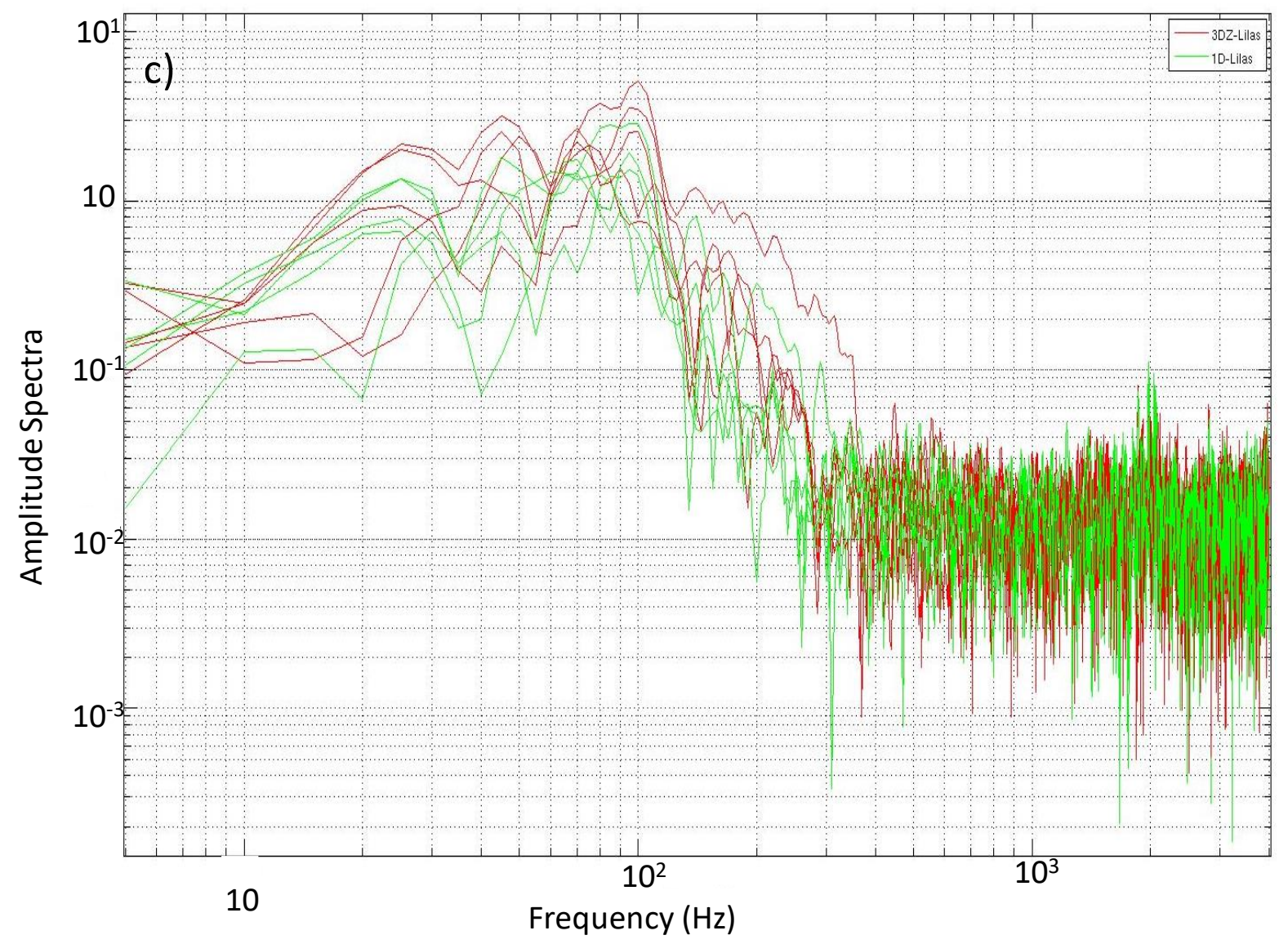




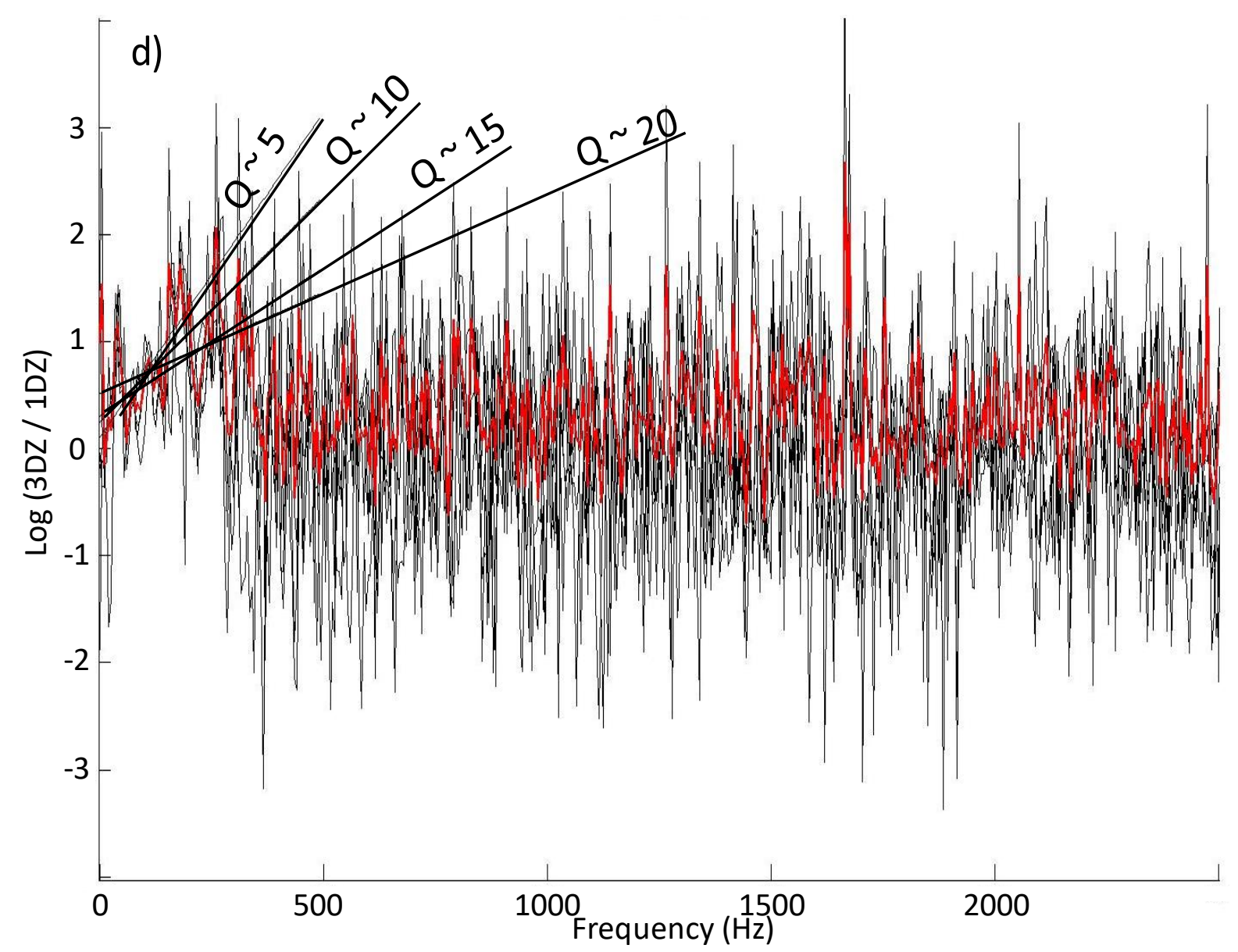

Figure 11 : amplitude spectra and spectral ratios of signal from block drops carried out just below the Lilas station, a) considering the entire signal, in green 1DZ sensor and in red 3DZ sensor. b) Spectral ratios with several possible linear regressions and the corresponding Q values, in red average spectrum. c) spectra of the P-wave first arrival and d) associated spectral ratio, in re, average spectrum. 
a)

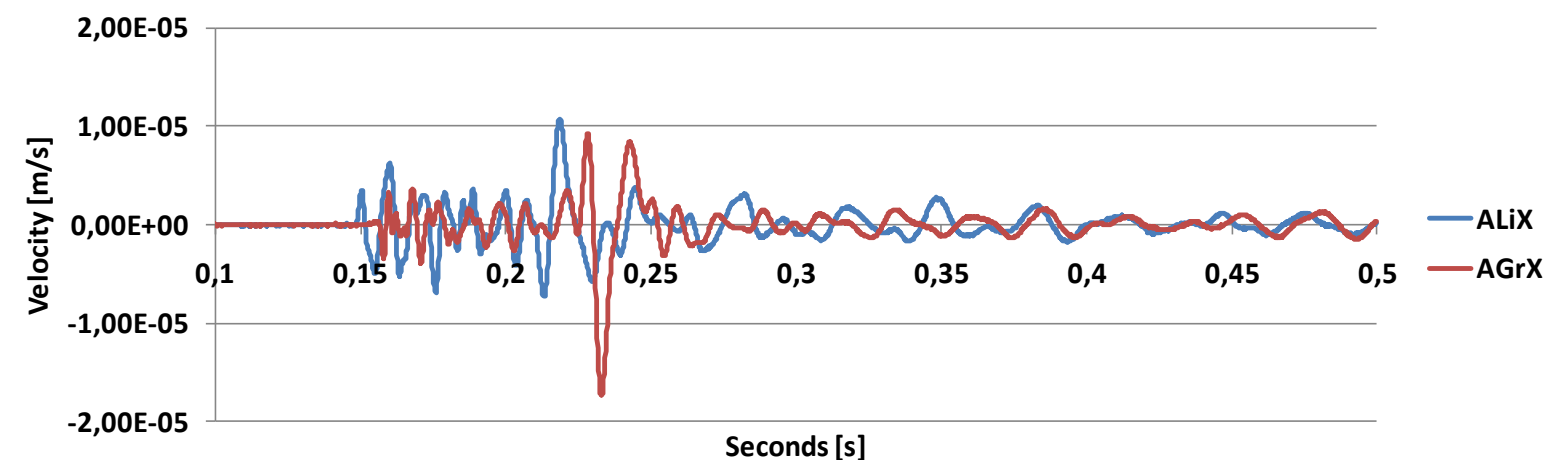

b)

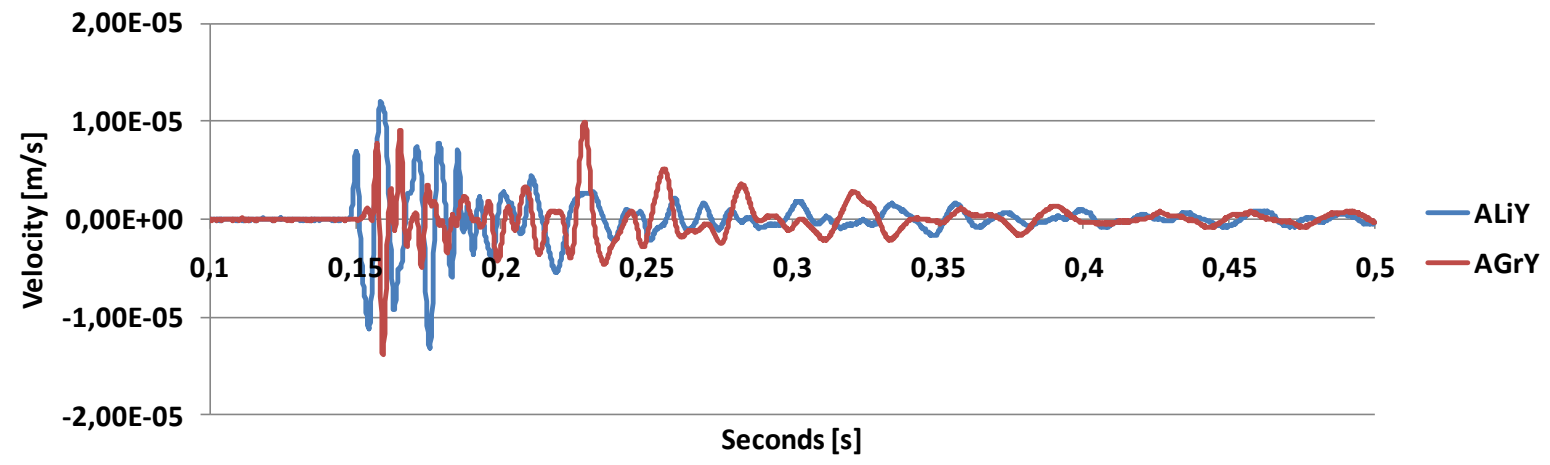

c)

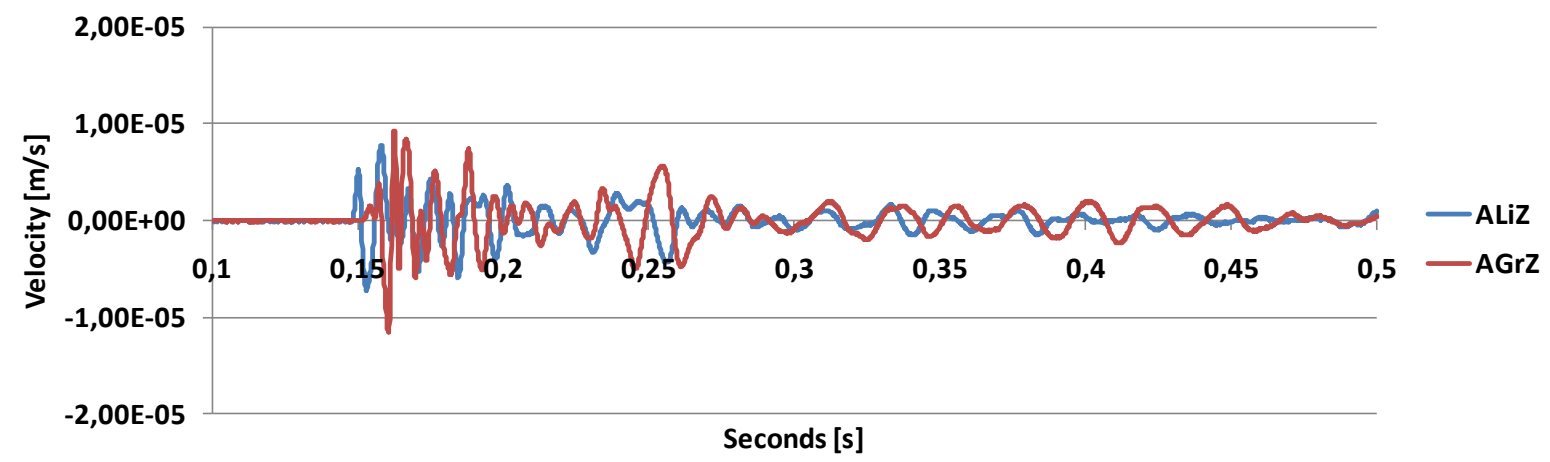

Figure 12 : superimposition of a) X, b) Y and c) Z component of 3D sensors of stations Lilas and Groseilliers for the blast 5a (1 $000 \mathrm{~g})$ located at the same distance from the two stations. 
a)

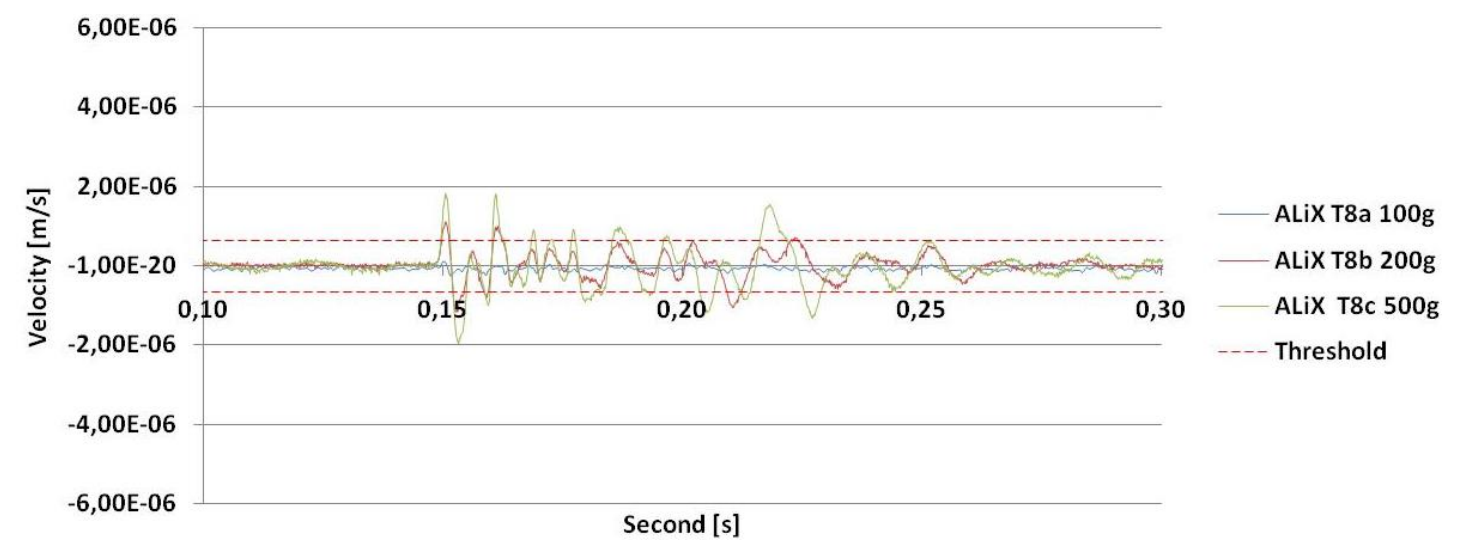

b)

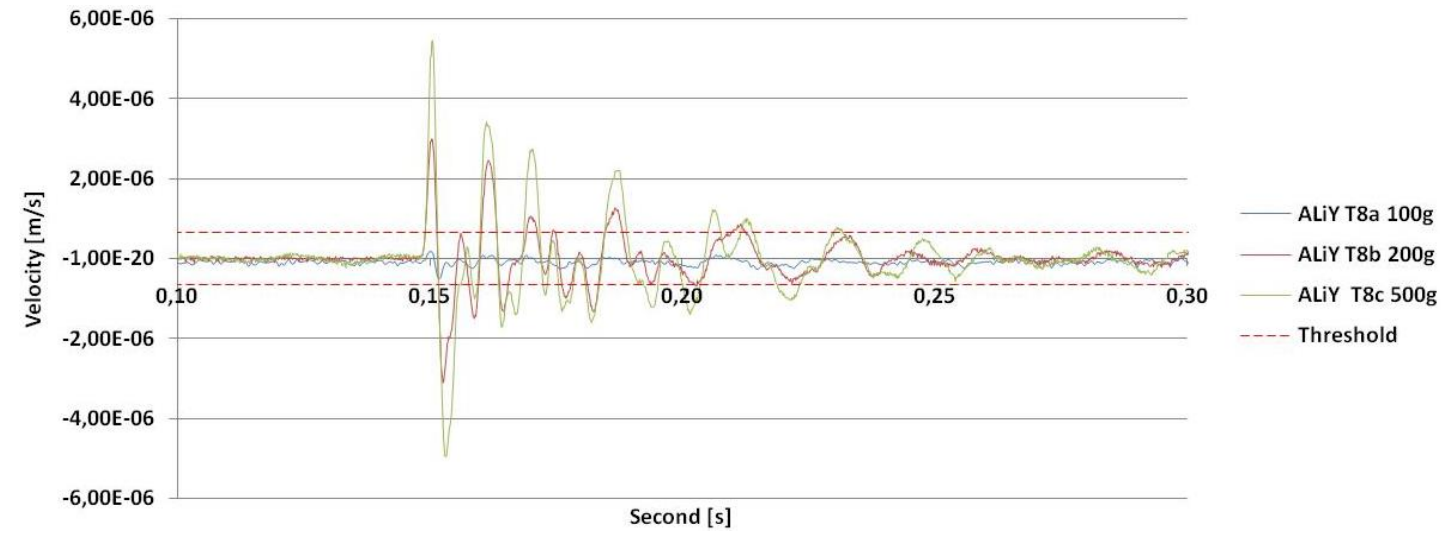

c)

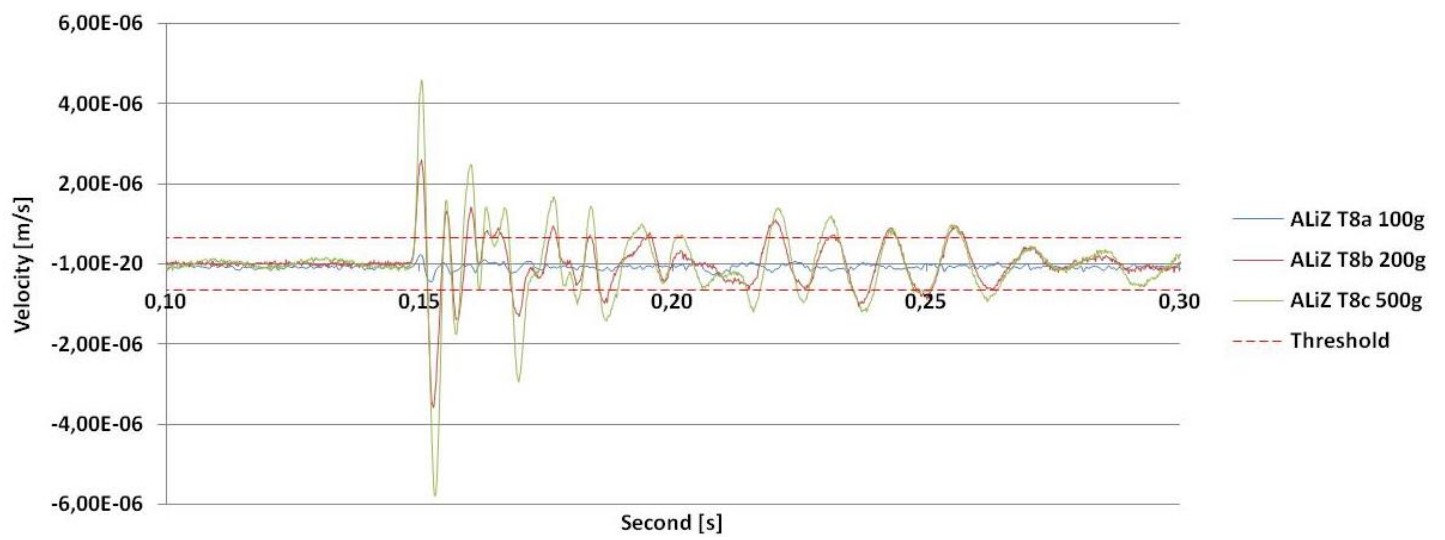

Figure 13 : superimposition of the blasts $8 \mathrm{a} 100 \mathrm{~g}$, $8 \mathrm{~b} 200 \mathrm{~g}$ and $8 \mathrm{c} 500 \mathrm{~g}$ signals recorded at the 3D sensor of the Lilas station : a) X, b) Y and c) Z components. 


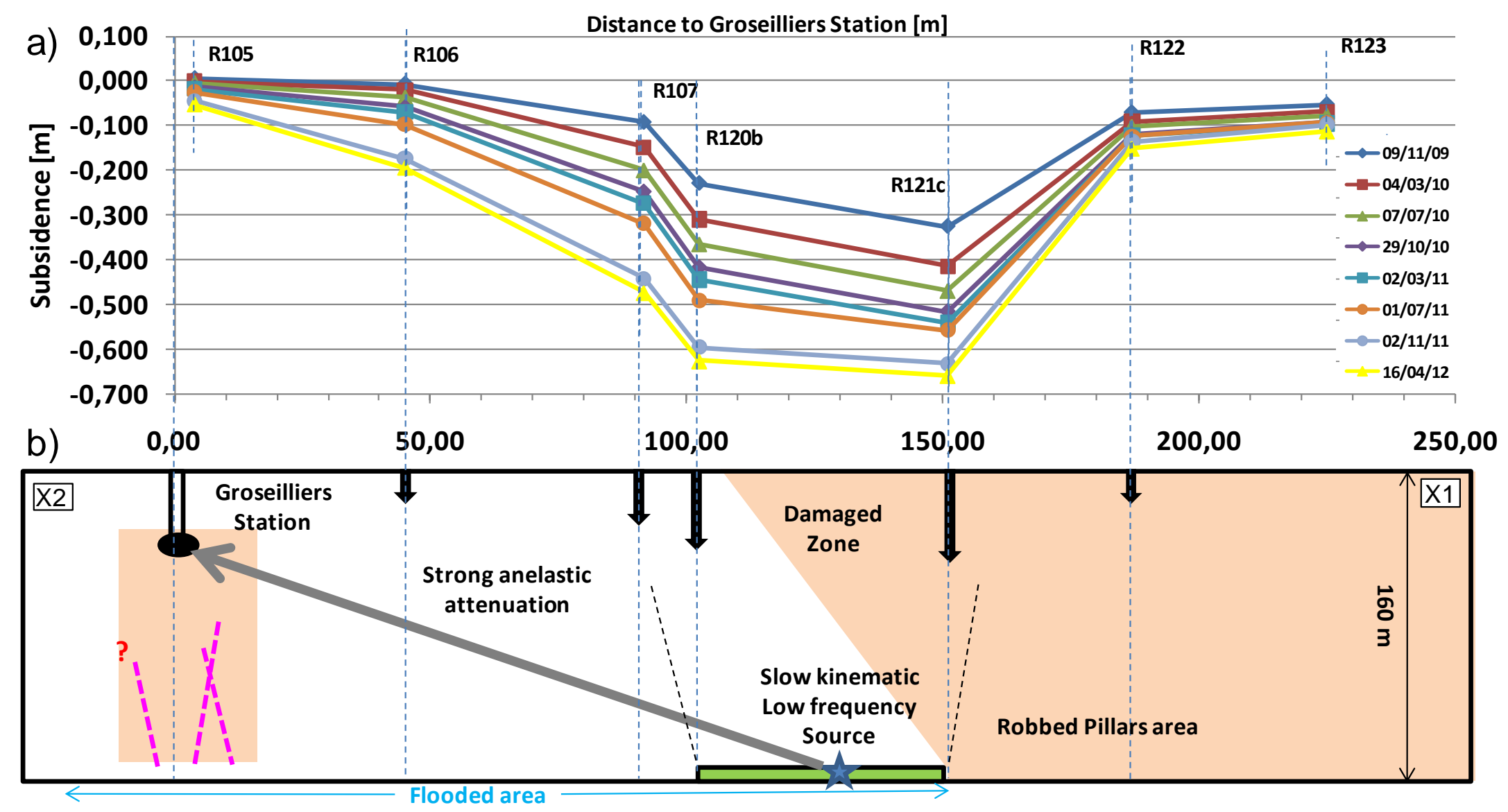




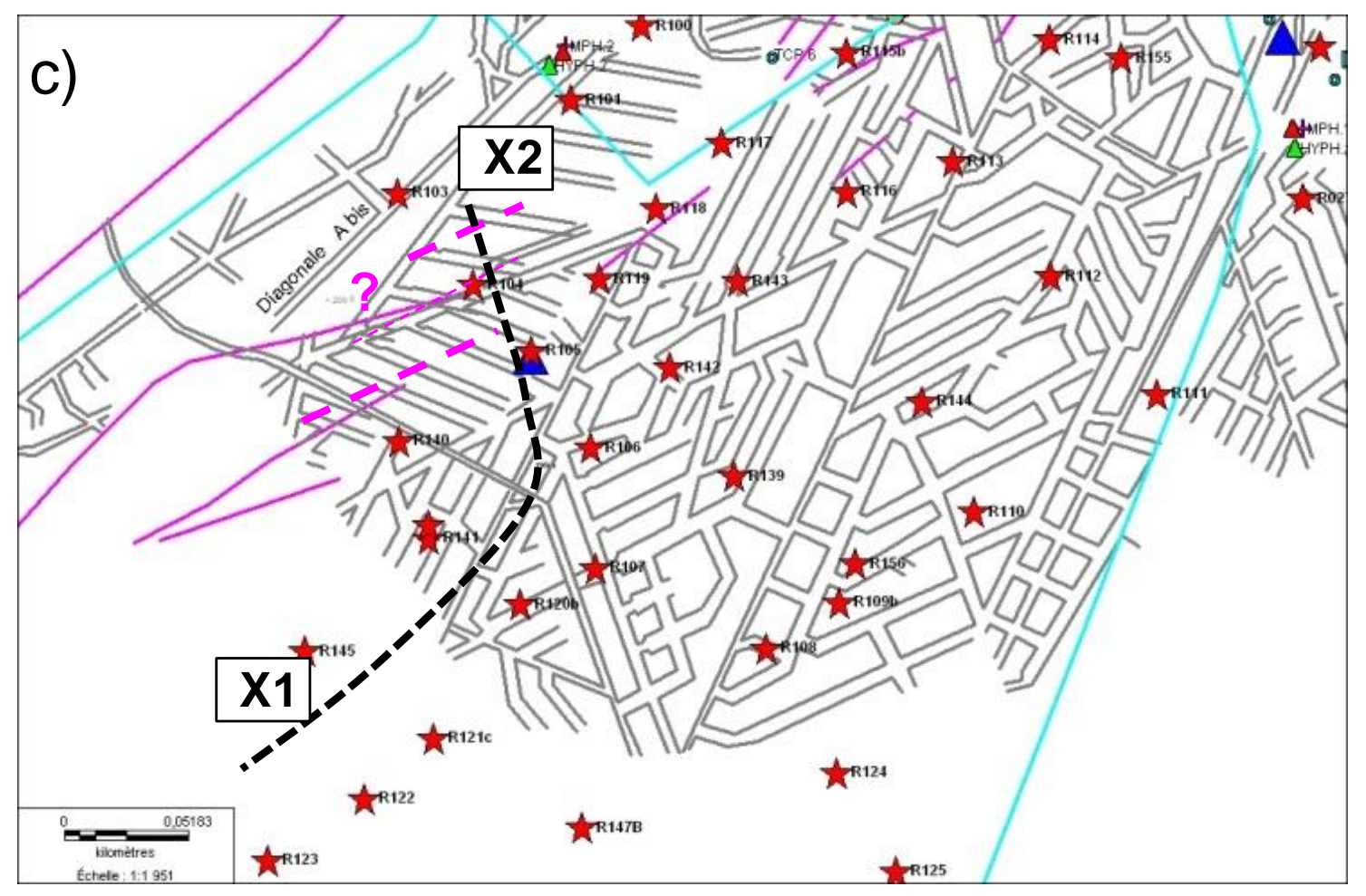

Figure 14 : summary of the hypothesis to explain the lack of detection of the seismic precursory of the subsidence. a) subsidence profile of points along a cross section located between X1 and X2 of the c) figure. b) schematic cross section between X1 and X2 and interpretation. 


\section{References :}

Abdul-Wahed, M.K., Senfaute, G., Piguet, J.P., Source location estimation using single station three-component seismic data, Rock Mechanics - A Challenge for Society: Proceedings of the ISRM Regional Symposium (Eurock 2001, Espoo, Finland, 4 - 7 June 2001).

Alheib, M. (2012), Mine d'or de Salsigne (Aude, Languedoc-Roussillon) : Analyse préliminaire des causes de l'événement sismique du 15 novembre 2011Rep., Ineris, DRS-12-13067109119A.

Balland, C. (2008), Expérimentation de calage microsismique - sites de Maxéville et NancyRep., Ineris-DRS-08-91469-11613A

Balland, C., J. Morel, G. Armand, and W. Pettitt (2009), Ultrasonic velocity survey in CallovoOxfordian argillaceous rock during shaft excavation, International Journal of Rock Mechanics and Mining Sciences, 46(1), 69-79.

Bardainne, T., and E. Gaucher (2010), Constrained tomography of realistic velocity models in microseismic monitoring using calibration shots, Geophysical Prospecting, 58(5), 738-752, doi:10.1111/j.1365-2478.2010.00912.x.

Barton, N. (2007), Rock Quality, Seismic Velocity, Attenuation and Anisotropy, 729 pp., Taylor \& Francis.

Bennani, M., and F. Homand (2004), Les Formations de couverture au droit des zones d'aléa d'effondrement brutalRep., Géodéris.

Bennani, M., J.-P. Josien, and P. Bigarré (2003), Surveillance des risques d'effondrement dans l'après-mine, besoins, méthodes, in Après-mines 2003, edited, Nancy.

Bigarré, P., M. Bennani, I. Contrucci, E. Klein, H. Baroudi, R. Hadadou, I. Vuidart, and J. P. Josien (2011), Microseismic monitoring strategy as a key component of post-mining risk management: review and feedback experience on the past decade, paper presented at 12th ISRM International Congress on Rock Mechanics, "Harmonizing Rock Mechanics and the Environment", Beijing, China, 18 - 21 October 2011.

Brune, J.N., 1970. Tectonic stress and the spectra of seismic shear waves from earthquakes. Journal of geophysical research 75, 4997-5009

Caro Cuenca, M., A. J. Hooper, and R. F. Hanssen (2013), Surface deformation induced by water influx in the abandoned coal mines in Limburg, The Netherlands observed by satellite radar interferometry, Journal of Applied Geophysics, 88, 1-11, doi:https://doi.org/10.1016/j.jappgeo.2012.10.003.

Cesca, S., Rohr, A. \& Dahm, T. J Seismol (2013), Discrimination of induced seismicity by full moment tensor inversion and decomposition, 17: 147. https://doi.org/10.1007/s10950012-9305-8.

Contrucci, I., M. Bennani, P. Bigarré, and P. Dominique (2013), Activité microsismique et caractérisation de la détectabilité des réseaux de surveillance du bassin houiller de Gardanne, in AGAP, edited, Nancy, doi:DOI: 10.13140/2.1.4100.7681.

Contrucci, I., E. Klein, P. Bigarré, A. Lizeur, A. Lomax, and M. Bennani (2010), Management of Post-mining Large-scale Ground Failures: Blast Swarms Field Experiment for Calibration of Permanent Microseismic Early-warning Systems, Pure and Applied Geophysics, 167(12), 43-62.

Contrucci, I., E. Klein, N. T. Cao, X. Daupley, and P. Bigarre (2011), Multi-parameter monitoring of a solution mining cavern collapse: First insight of precursors, Comptes Rendus Geoscience, 343(1), 1-10, doi:10.1016/j.crte.2010.10.007.

Couffin, S., P. Bigarré, M. Bennani, and J. P. Josien (2003), Permanent real time microseismic monitoring of abandoned mines for public safety, paper presented at Field Measurements in Geomechanics, Oslo, Norway, , 23-26 September 2003. 
Dahm, T., G. Manthei, and J. Eisenblatter (1998), Relative moment tensors of thermally induced microcracks in salt rock, Tectonophysics, 289(1-3), 61-74.

Deck, O. (2002), Etude des conséquences des affaissements miniers sur le bâti. Propositions pour une méthodologie d'évaluation de la vulnérabilité du bâti, 242 pp, Lorraine, Nancy.

Didier, C. (2007), La politique française de prévention des risques liés à l'après-mine, RÉALITÉS INDUSTRIELLES 86-97.

Dominique, P., F. L. Hoher, and M. Bendif (2012), Instrumentation d'une petite crise sismique à Salsigne, Aude. , paper presented at Journées Nationales de Géotechnique et de Géologie de l'Ingénieur JNGG2012, Bordeaux, 4-6 juillet 2012.

GEODERIS (2010), Expertise géotechnique de l'affaissement survenu à Angevillers en octobre 2009, Rapport d'avancementRep., GEODERIS, E2010/041DE - 10LOR3500.

GISOS (2007), Synthèse des travaux de recherche après-mine Fer, http://gisos.ensg.inplnancy.fr/fileadmin/File/Rapports synthese/GISOS $\% 20$ synth $\% 20 \mathrm{fer} \% 202007$ c.pdfRep., $54 \mathrm{pp}$.

Goldbach, O. (2010), What is the seismic risk of mine flooding, paper presented at CSIR 3rd Biennial Conference 2010. Science Real and Relevant, Pertoria, South Africa, 30 August 01 September 2010, .

Homand, F., and G. Dagallier (2004), Etude des formations de couverture des zones à risque d'effondrement brutal non écartéRep., LAEGO.

Ikeda, K., H. Ohshima, and T. Sakurai (1981), The property and the seismic wave velocity of fractured zone, paper presented at Proceeding of International Symposium. on Weak Rock, Tokyo.

Kinscher, J. (2015), The analysis and interpretation of microseismicity induced by a collapsing solution mining cavity, thèse de doctorat, Université de Lorraine.

Kinscher, J., P. Bernard, I. Contrucci, A. Mangeney, J. P. Piguet, and P. Bigarre (2015), Location of microseismic swarms induced by salt solution mining, Geophysical Journal International, 200(1), 337-362, doi:10.1093/gji/ggu396.

Kinscher, J., S. Cesca, P. Bernard, I. Contrucci, A. Mangeney, J. P. Piguet, and P. Bigarré (2016), Resolving source mechanisms of microseismic swarms induced by solution mining, Geophysical Journal International, 206(1), 696-715, doi:10.1093/gji/ggw163.

Knopoff, L. (1964), Q, Reviews of Geophysics, 2(4), 625-660.

Li, Y., T.-H. Yang, H.-L. Liu, H. Wang, X.-G. Hou, P.-H. Zhang, and P.-T. Wang (2016), Realtime microseismic monitoring and its characteristic analysis in working face with highintensity mining, Journal of Applied Geophysics, 132, 152-163, doi:https://doi.org/10.1016/j.jappgeo.2016.07.010.

Lomax, A., and Curtis, A., Fast, probabilistic earthquake location in 3D models using oct-tree importance sampling, European Geophysical Society (Nice 2001).

Lomax, A., and R. Snieder (1995), Identifying sets of acceptable solutions to non-linear, geophysical inverse problems which have complicated misfit functions, Nonlinear Processes in Geophysics, 2(3-4), 222-227.

Malovichko, D. A., R. Dyagilev, D. Y. Shulakov, P. Butyrin, and S. V. Glebov (2009), Seismic monitoring of large-scale karst processes in a potash mine, in Controlling seismic hazard and sustainable development of deep mines, edited, pp. 989-1002.

Malovichko, D. A., R. A. Dyagilev, D. Y. Shulako, and P. G. Butyrin (2001), Sesismic monitoring of large-scale karst processes in a potash mine, Russian Academy of Sciences National Geophysical Committee - International Association of Seismology and Physics of the Earth's Interior of the International Union of Geodesy and Geophysics, 120-125.

Malovichko, D. A., O. I. Kadebskaya, D. Y. Shulakov, and P. G. Butyrin (2010), Local seismologic observations of karst processes, Izvestiya, Physics of the Solid Earth, 46(1), 57 73, doi:10.1134/s1069351310010052. 
Marot, M., J. Kinscher, S. Coccia, I. Contrucci, E. Klein, and P. Bigarré (2014), Mine Induced Seismicity: From a Passive Microseismic Monitoring in Complex Near-Field Underground Conditions to an Open \& Accessible Database, in Fifth EAGE Passive Seismic Workshop., edited.

Maubeuge, P.-L. (1955), Observations géologiques dans l'est du bassin de Paris: Terrains triasiques moyens-supérieurs et jurassiques inférieurs-moyens, 1148 pp., Nancy, France.

Mendecki, A. J. (1996), Seismic Monitoring in Mines, Springer Netherlands.

Miller, A., J. A. Richards, D. M. McCann, C. W. A. Browitt, and P. D. Jackson (1989), Microseismic Techniques for Monitoring Incipient Hazardous Collapse Conditions above Abandoned Limestone Mines, Quarterly Journal of Engineering Geology, 22(1), 1-18, doi:10.1144/gsl.qjeg.1989.022.01.01.

Montagne, A., E. Tincelin, J. Astier, and J.-L. Varoquaux (1992), Les mines de fer de Lorraine, 255 pp., Paris, 56 Av. de Wagram, 75854 Cedex 17 : UIMM, 1992, Paris : Impr. ADASE, Paris.

Oberti, G., E. Carabelli, L. Goffi, and P. P. Rossi (1979), Study of an orthotropic rock mass: experimental techniques, comparative analysis of results, paper presented at Proc. of 4th IRSM, Montreux.

Ogasawara, H., et al. (2002), Microseismicity induced by heavy rainfall around flooded vertical ore veins, Pure and Applied Geophysics, 159(1-3), 91-109, doi:10.1007/p100001269.

Orlecka-Sikora, B., S. Lasocki, G. Lizurek, and L. Rudzinski (2012), Response of seismic activity in mines to the stress changes due to mining induced strong seismic events, International Journal of Rock Mechanics and Mining Sciences, 53, 151-158, doi:10.1016/j.ijrmms.2012.05.010.

Picotti, S., and J. M. Carcione (2006), Estimating seismic attenuation (Q) in the presence of random noise, Journal of Seismic Exploration, 15(2), 165-181.

Sain, K., A. K. Singh, N. K. Thakur, and R. Khanna (2009), Seismic quality factor observations for gas-hydrate-bearing sediments on the western margin of India, Marine Geophysical Researches, 30(3), 137-145, doi:10.1007/s11001-009-9073-1.

Senfaute, G., M. Abdul Wahed, J.-P. Piguet, and J.-P. Josien (2000), Technique d'écoute microsismique appliquée au risque d'effondrement dans les mines du bassin ferrifère lorrain, Revue Française de Géotechnique, 92, 57-62.

Sjogren, B., A. Ofsthus, and J. Sandberg (1979), Seismic classification of rock mas qualities, Geophysical Prospecting, 27, 409-442.

Srinivasan, C., Y. Willy, and P. C. Nawani (2009), Post-Closure seismicity in the mines of Kolar Gold fields, , paper presented at RaSiM 7 (2009), Controlling Seismic Hazard and Sustainable Development of Deep Mines.

Tarantola, A. and Valette, B. (1982). Generalized Nonlinear Inverse Problems Solved using the Least Squares Criterion. Reviews of Geophysics and Space Physics, 20(2), 219-232.

Tastet, J., I. Contrucci, E. Klein, P. Bigarré, and L. Driad-Lebeau (2007), Large-scale field experiment to calibrate microseismic source parameters applied to realtime monitoring of post-mining instabilities, paper presented at 11 th congress of the international society for rock mechanics, Lisbon, Portugal, 9-13 july 2007.

Thomsen, F. (1986), Weak elastic anisotropy, Geophysics, 51(10), 1954-1966.

Toksoz, M. N., D. H. Johnston, and A. Timur (1979), Attenuation of Seismic-Waves in Dry and Saturated Rocks .1. Laboratory Measurements, Geophysics, 44(4), 681-690.

Toksöz, M. N., D. H. Johnston, and A. Timur (1979), Attenuation of seismic waves in dry and saturated rocks: I. Laboratory measurements, GEOPHYSICS, 44(4), 681-690, doi:10.1190/1.1440969.

Trifu, C. I., and V. Shumila (2010), Microseismic Monitoring of a Controlled Collapse in Field II at Ocnele Mari, Romania, Pure and Applied Geophysics, 167(1-2), 27-42, doi:10.1007/s00024-009-0013-4. 
Um, J., and C. Thurber (1987), A fast algorithme for two-point seismic ray tracing, Bulletin of the Seismological Society of America, 77(3), 972-986.

Urbancic, T. I., and C.-I. Trifu (2000), Recent advances in seismic monitoring technology at Canadian mines, Journal of Applied Geophysics, 45(4), 225-237, doi:https://doi.org/10.1016/S0926-9851(00)00030-6.

Zamfirescu, F., M. Mocuta, T. Constantinescu, C. Nita, and A. Danchiv (2007a), The main causes and processes of instability evolution at Field II of Ocnele Mari - Romania, paper presented at Solution Mining Research Institute Spring Meeting, Basel, Switzerland, 28 April - 2 May 2007.

Zamfirescu, F., M. Mocuta, R. Dima, T. Constantinescu, and C. Nita (2007b), A technical solution for the collapse fragmentation of the Field II cavern - Ocnele Mari, Romania, paper presented at Solution Mining Research Institute Spring Meeting, Basel, Switzerland, 28 April - 2 May 2007. 